\title{
BIOACTIVE MOLECULES FOR REGENERATIVE PULP CAPPING
}

\author{
L.L.E. Whitehouse ${ }^{1}$, N.H. Thomson ${ }^{1,2}$, T. Do ${ }^{1}$ and G.A. Feichtinger ${ }^{3, *}$ \\ ${ }^{1}$ Division of Oral Biology, School of Dentistry, Faculty of Medicine and Health, University of Leeds, \\ Leeds, LS2 9LU, UK \\ ${ }^{2}$ School of Physics and Astronomy, University of Leeds, Leeds, LS2 9JT, UK \\ ${ }^{3}$ School of Biomedical Sciences, Faculty of Biological Sciences, University of Leeds, Leeds, LS2 9JT, UK
}

\begin{abstract}
Since the discovery of bioactive molecules sequestered in dentine, researchers have been exploring ways to harness their activities for dental regeneration. One specific area, discussed in this review, is that of dental-pulp capping. Dental-pulp caps are placed when the dental pulp is exposed due to decay or trauma in an attempt to enhance tertiary dentine deposition. Several materials are used for dental-pulp capping; however, natural biomimetic scaffolds may offer advantages over manufactured materials such as improved aesthetic, biocompatibility and success rate. The present review discusses and appraises the current evidence surrounding biomimetic dental-pulp capping, with a focus on bioactive molecules sequestered in dentine. Molecules covered most extensively in the literature include transforming growth factors (TGF- $\beta$ s, specifically TGF- $\beta 1$ ) and bone morphogenetic proteins (BMPs, specifically BMP-2 and BMP-7). Further studies would need to explore the synergistic use of multiple peptides together with the development of a tailored scaffold carrier. The roles of some of the molecules identified in dentine need to be explored before they can be considered as potential bioactive molecules in a biomimetic scaffold for dental-pulp capping. Future in vivo work needs to consider the inflammatory environment of the dental pulp in pulpal exposures and compare pulp-capping materials.
\end{abstract}

Keywords: Dental pulp, pulp cappping, pulp regeneration, biologics, biomaterials, growth factors, dentistry, dentinogenesis, regenerative medicine, biomaterials.

*Address for correspondence: School of Biomedical Sciences, Faculty of Biological Sciences, University of Leeds, Leeds, UK

Email: g.feichtinger@leeds.ac.uk

Copyright policy: This article is distributed in accordance with Creative Commons Attribution Licence (http://creativecommons.org/licenses/by-sa/4.0/).

\begin{tabular}{|c|c|c|c|}
\hline & List of abbreviations & $\begin{array}{l}\text { GDNF } \\
\text { GM-CSF }\end{array}$ & $\begin{array}{l}\text { glial-derived neurotrophic factor } \\
\text { granulocyte macrophage colony- }\end{array}$ \\
\hline $\mathrm{ADM}$ & adrenomedullin & & stimulating factor \\
\hline BDNF & brain-derived neurotrophic factor & Ig & immunoglobulin \\
\hline BMP & bone morphogenetic protein & IGF & insulin-like growth factor \\
\hline BSP & bone sialoprotein & IGFBP & IGF binding protein \\
\hline CGRP & calcitonin-gene-related peptide & $\mathrm{IL}$ & interleukin \\
\hline CXCL12 & C-X-C motif chemokine 12 & HGF & hepatocyte growth factor \\
\hline DMP1 & dentine matrix protein 1 & LAP & latency-associated pro-peptide \\
\hline DPC & dentine-pulp-complex & LTBP-1 & latent TGF- $\beta 1$ binding protein \\
\hline DPP & dentine phosphoprotein & MAPK & mitogen-activated protein kinase \\
\hline DPSC & dental pulp stem cells & MEPE & matrix extracellular \\
\hline DSPP & dentine sialophosphoprotein & & phosphoglycoprotein \\
\hline DSP & dentine sialoprotein & MMP & matrix metalloproteinase \\
\hline ECM & extracellular matrix & MTA & mineral trioxide aggregate \\
\hline EGF & epidermal growth factor & NGF & nerve growth factor \\
\hline FGF & fibroblast growth factor & OPN & osteopontin \\
\hline G-CSF & granulocyte colony-stimulating & PCA & pulp-capping agent \\
\hline & factor & PDGF & platelet-derived growth factor \\
\hline
\end{tabular}




$\begin{array}{ll}\text { PIGF } & \text { placental growth factor } \\ \text { SCF } & \text { stem cell factor } \\ \text { SIBLING } & \begin{array}{l}\text { N-linked glycoprotein } \\ \text { small leucine-rich proteoglycans }\end{array} \\ \text { SLRPs } & \begin{array}{l}\text { secreted protein, acidic and rich in } \\ \text { cysteine }\end{array} \\ \text { SPARC } & \text { transforming growth factor } \\ \text { TGF } & \text { vascular endothelial growth factor } \\ \text { VEGF } & \text { wingless/integrated }\end{array}$

\section{Introduction}

Caries (dental decay) is the most prevalent noncommunicable human disease and is linked to "a low quality of life" (^̊kesson et al., 2016). The Global Burden of Disease Study estimated that 3.58 billion people worldwide have untreated caries (Web ref. 1). Indirect costs (for example, work absences) due to caries worldwide amount to a loss of 144 billion USD/ year (Listl et al., 2015), highlighting the significant impact caries have at a global level.

The crowns of teeth are made of enamel, dentine and pulp. Dentine is a living structure, with an inorganic content similar to bone, being predominantly hydroxyapatite, calcium and phosphate salts (Sloan, 2015). The dental pulp, which is encased by dentine, contains vessels, nerves and cells that maintain the vitality of the tooth. Dentine and pulp are inextricably linked (termed together as DPC). They share embryological origin [both derive from the ectomesenchyme (Zohrabian et al., 2015)] and both release factors acting on the other (Smith, 2003), facilitating a state of homeostasis and, when necessary, regeneration and repair. The DPC is the only part of the tooth with in vivo regenerative potential and is being increasingly studied for its potential in biological-scaffold production (HashemiBeni et al., 2017; Qu et al., 2015) and dental-tissue regeneration.

Dentineogenesis is the production of dentine and, in a healthy body, it is performed by odontoblasts (dentine-producing cells). Odontoblasts are largely inactive after primary dentineogenesis (Table 1). However, following insult to the pulp, odontoblasts play a role in wound healing in the form of reactionary dentineogenesis, where they lay down dentine to seal the vital pulp from the insult. Should the stimulus be great enough to kill the odontoblasts (such as a significant trauma or deep caries), DPSCs will migrate to the site of injury, differentiate into odontoblast-like cells and begin laying down dentine, a process called reparative dentineogenesis. This results in a dentine bridge, sealing the precious pulp from further insults (McLachlan et al., 2003).

Tertiary dentineogenesis is driven by a dental injury, although the interplay between inflammation and regeneration is a delicate balance. Typically, exposed dental pulps are inflamed and often infected. It is generally accepted that only when infection and inflammation are under control will reparative actions occur in the dental pulp (Cooper et al., 2014). Many of the cytokines and growth factors involved in tertiary dentineogenesis, at high doses, may lead to pulpal death and prevent DPSC differentiation (Cooper et al., 2014). However, certain inflammatory cells (such as macrophages and dendritic cells) have also been shown to stimulate odontoblast differentiation (Goldberg et al., 2008 a; Saito et al., 2011). Similarly, molecules upregulated in caries, such as C5a and stromal cell-derived factor 1/CXCL12, can recruit immune cells as well as DPSCs (Cooper et al., 2014). These studies highlight the intricate, delicate and vital interplay between inflammation and regeneration in tertiary dentineogenesis and caries.

Reparative dentineogenesis is a complex process, as DPSCs need to be recruited to the site of injury, undergo differentiation and deposit dentine. Understandably, this is more time-consuming than reactionary dentineogenesis and, because of this, it is often ineffective at sealing the pulp from the insult. Significantly, this process is driven by the release of bioactive molecules (including growth factors, cytokines and other matrix molecules) sequestered within dentine during primary dentineogenesis and released following dentine damage. These molecules can stimulate reparative and reactionary dentineogenesis (Smith et al., 2012) and are summarised in Fig. 1.

When a pulp is exposed because of a trauma, mechanical action (typically iatrogenic) or caries, the clinician has the choice of either attempting to save the pulp (through a direct pulp cap) or not [leading to a root canal treatment (endodontics) or an extraction]. PCAs attempt to seal the pulp by encouraging tertiary dentine deposition. Direct pulp caps can be technically challenging to perform successfully and correctly, with Bjørndal et al. (2017) reporting success rates as low as $9 \%$ after pulp exposures in a 5-year follow-up. When the pulp is exposed, the tooth needs to be isolated (ideally with a rubber dam), any further caries removed, the area cleaned/wound lavage, haemostasis achieved, the PCA prepared/mixed, placed and allowed to set (if required) and the cavity restored. Clinicians may also decide to remove some of the superficial pulp that has been exposed (termed as partial pulpotomy), in an attempt to remove any inflamed pulpal tissue that may impair healing (Bjørndal et al., 2019). Besides the PCA used, numerous other factors may influence the success rates of a pulp cap, such as:

- bacterial microleakage from the restoration, operative debris from the cavity preparation, uncontrolled haemorrhage (Murray et al., 2002),

- experience of the operator, type of cavity (interdental/occlusal) (Ritter, 2007),

- time to permanent restoration (Mente et al., 2014),

- type of exposure (carious/mechanical/trauma) (Ritter, 2007),

- type of lavage/haemostasis agent used (Tüzüner et al., 2012). 
Table 1. Comparison of primary, secondary and tertiary dentine.

\begin{tabular}{|c|c|}
\hline Dentine type & When/where present \\
\hline Primary & $\begin{array}{c}\begin{array}{c}\text { Produced during initial tooth formation, before the tooth erupts. Produced by } \\
\text { odontoblasts. }\end{array} \\
\end{array}$ \\
\hline Secondary & $\begin{array}{l}\text { Deposited at a slow rate throughout life after primary dentinogenesis by } \\
\text { odontoblasts, reducing the size of the pulp with age. Formed by odontoblasts. }\end{array}$ \\
\hline \multirow[b]{2}{*}{ Tertiary } & $\begin{array}{l}\text { Reactionary: formed following mild/"slow and chronic" insult to the pulp. } \\
\text { Formed by odontoblasts. Tubular structure, similar to primary dentine. }\end{array}$ \\
\hline & $\begin{array}{l}\text { Reparative: formed following significant insult to the pulp, resulting in } \\
\text { odontoblast death. Formed by odontoblast-like cells derived from resident } \\
\text { DPSCs. Atubular structure, often showing some similarities to bone. }\end{array}$ \\
\hline
\end{tabular}

A pulp cap is deemed successful if at 75-90 d a dentine bridge has formed and the tooth remains vital (Stanley and Pameijer, 1997), although typically a dentine bridge begins to form within $30 \mathrm{~d}$ of the original pulp cap and is largely completed by $130 \mathrm{~d}$ (Hargreaves and Cohen, 2010). No PCAs currently available are perfect and, considering the prevalence of caries, it is imperative that cost-effective materials with high success rates, desirable clinical outcomes and suitable handling qualities are available for clinical use. Furthermore, evidence supporting the use of many PCAs is generally lacking, with poor quality clinical studies often including sound teeth, limited follow-up time, lack of histological data, young healthy patients and tooth isolation (Hilton, 2009), which often make comparison to real-life clinical work challenging.

\section{Pulp-capping materials}

There are many pulp-capping materials/agents available commercially, with $\mathrm{Ca}(\mathrm{OH})_{2}$ and $\mathrm{Ca}_{2} \mathrm{SiO}_{4}$ based materials (MTA and other $\mathrm{Ca}_{3} \mathrm{SiO}_{5}$-based cements) being the most used in clinical practice.

Of the more commonly used PCAs, $\mathrm{Ca}(\mathrm{OH})_{2}$ has been used the longest (having been first explored in the 1920s) and for many years has been considered the gold standard for a direct pulp cap (Hilton, 2009; Qureshi et al., 2014). $\mathrm{Ca}(\mathrm{OH})_{2}$ is often considered as the benchmark to compare newer PCAs against - in vivo and in vitro - and there is a wealth of literature supporting its use. The high alkalinity of $\mathrm{Ca}(\mathrm{OH})_{2}$ eliminates micro-organisms, providing a favourable environment for dentineogenesis. However, this has negative implications too, making $\mathrm{Ca}(\mathrm{OH})_{2}$ cytotoxic, resulting in further pulpal necrosis (Youssef et al., 2019). The exact process of dentineogenesis in a $\mathrm{Ca}(\mathrm{OH})_{2}$ pulp-capped tooth remains contentious, with some studies supporting the notion that irritation, inflammation and necrosis in the pulp caused by $\mathrm{Ca}(\mathrm{OH})_{2}$ initiate dentineogenesis via an unknown pathway and others suggesting that dentineogenesis is due to $\mathrm{Ca}(\mathrm{OH})_{2}$ facilitating release of bioactive molecules sequestered in dentine (Bjørndal et al., 2019; Graham et al., 2006; Hilton, 2009); or potentially a mixture of the two. $\mathrm{Ca}(\mathrm{OH})_{2}$ presents numerous issues as a PCA, such as high solubility, lack of adhesion to dentine and 'tunnel defects' in the reparative dentine formed (Qureshi et al., 2014).

MTA is newer to the commercial market than $\mathrm{Ca}(\mathrm{OH})_{2}$, although has been used for pulp capping since the 1990s (Zafar et al., 2020), and is thought to have higher success rates than $\mathrm{Ca}(\mathrm{OH})_{2}$ (da Rosa et al., 2018b; Paula et al., 2018; Zhu et al., 2015). Moisture is required for MTA to set and, when water is added, a colloidal gel composed of calcium oxide crystals is formed (calcium silicate hydrate) and $\mathrm{Ca}(\mathrm{OH})_{2}$ is released, imparting much of the MTA's known antimicrobial activity (Zafar et al., 2020). MTA liberates numerous growth factors from dentine during pulp capping (Tomson et al., 2017). Although MTA would appear to be a good PCA based upon the success rates, there are numerous issues with its use, for example, long setting times ( $>2 \mathrm{~h}$ for some brands), discolouration of teeth, poor handling characteristics (due to its crumbly nature), risk of pulpal obliteration and high cost (Linsuwanont et al., 2017; Qureshi et al., 2014; Zafar et al., 2020). Due to the release of $\mathrm{Ca}(\mathrm{OH})_{2}$, MTA also has high alkalinity, which again is cytotoxic (Kim et al., 2019; Youssef et al., 2019). More recent modifications of MTA have attempted to remedy some of these problems (e.g., newer generation versions of MTA have faster setting times through the addition of either $\mathrm{CaSO}_{4}$ or $\mathrm{NaOCl}$, reduction in particle size or addition of substances to allow for light curing) and to reduce tooth discolouration (Zafar et al., 2020), although long-term studies demonstrating no reduction in efficacy are lacking.

Newer $\mathrm{Ca}_{3} \mathrm{SiO}_{5}$-based cements [for example, BioDentine $^{\mathrm{TM}}$ (Septodont, Niederkassel, Germany)] have been explored to overcome numerous issues of previous PCAs [for example, BioDentine ${ }^{\mathrm{TM}}$ has a shorter setting time than MTA and improved handling characteristics (Zafar et al., 2020)] but still problems exist [for example, tooth discolouration and age-dependent results (Lipski et al., 2018)]. Again, due to the high alkalinity of the material, $\mathrm{Ca}_{3} \mathrm{SiO}_{5}-$ based cements will have cytotoxic effects on the pulp (Youssef et al., 2019). No statistically significant differences in the various outcomes were found in a systematic review when MTA was compared to $\mathrm{Ca}_{3} \mathrm{SiO}_{5}$-based cements (Paula et al., 2018), although a significant lack of long-term cohort studies and 
randomised controlled trials were identified as a significant issue, partly due to the newness of the material.

A lack of a highly effective PCA is the driving motivator behind the exploration of more biomimetic approaches to pulp capping, with the hope of discovering and utilising key factors present during tertiary dentineogenesis to drive DPC regeneration. Many of the bioactive molecules within dentine can be liberated by current PCAs (Tomson et al., 2017) or through chemical treatment of the dentine (Zhao et al., 2000), although this release is poorly controlled in terms of frequency and volume. By applying these molecules extraneously, it may be possible to exploit their actions in a biomimetic pulp-capping agent to actively drive tertiary dentineogenesis, in a controlled manner, for pulp capping, maintaining the vitality of the tooth. These data can be used to inform dentineogenic scaffold design - allowing for the ideal biomimetic environment to be fabricated, which can include the bioactive molecules pertinent for reparative dentineogenesis - and provide an ideal environment for DPSC migration and differentiation, excluding noxious irritants present in many current PCAs and in the inflamed pulp. In essence, harnessing the positive reparative factors of tertiary dentineogenesis and excluding the negative factors that drive pulpal necrosis. Moreover, many of the scaffolds designed to carry bioactive molecules can also carry medicaments such as anti-inflammatories and antimicrobials, which will be of considerable benefit in controlling pulpal inflammation and any residual caries. In addition, many of these scaffolds also swell in the presence of moisture, which may be beneficial in providing a seal from the oral environment. When considering the possibility of a biomimetic PCA, it is important to remember that tertiary dentineogenesis occurs in the pulp and, by creating an environment similar to the dental pulp, it may be possible to speed up the process of reparative dentineogenesis with fewer unwanted side effects. As such, a scaffold loaded with biomimetic bioactive molecules may prove to be an ideal pulp-capping material, fulfilling the key requirements of a PCA, which include: 1 ) immediate seal of the dental cavity, protecting the pulp as a dentine bridge is forming; 2) biocompatibility and non-cytotoxic; 3) possess of bioactive properties

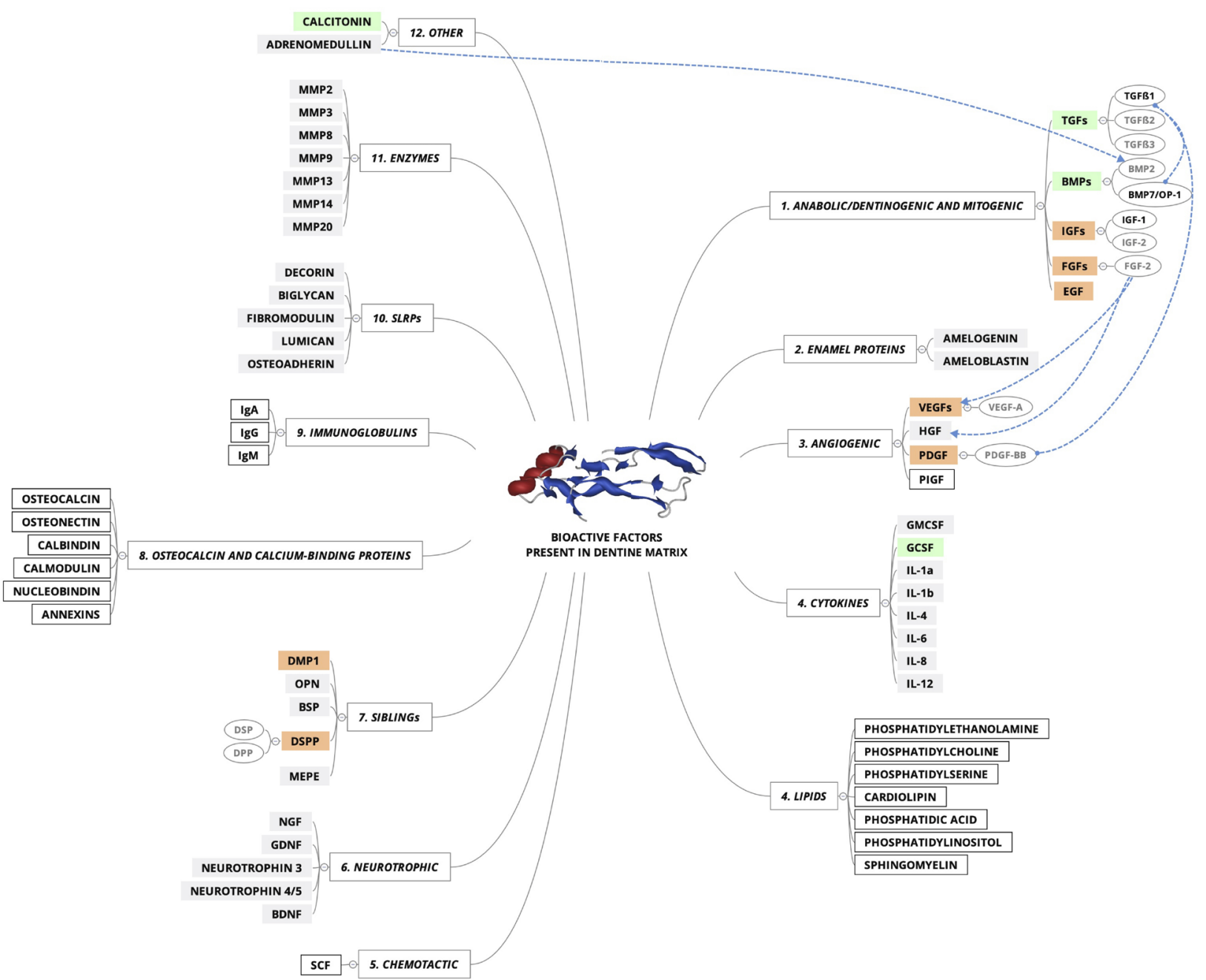

Fig. 1. Schematic diagram summarising the bioactive molecules sequestered in dentine that have been explored in the literature, and the present review, for pulp-capping dentineogenesis. Molecules with the most evidence supporting their use are in green, intermediate evidence in amber and little evidence in grey. Molecules in white have been included for completeness. Interactions are shown by arrows. 
capable of triggering the biological mechanisms for dentine-bridge production (Bjørndal et al., 2019).

Bioactive molecules, such as DNA (gene therapy) or proteins for dentinogenic pulp-capping may be added to scaffolds. Gene therapy eliminates the need for externally produced recombinant factors and gene transfection can enhance the efficacy of stem cell applications (Yang et al., 2009). Some bioactive molecules (for example BMPs) have a short half-life and are required in high concentrations at local sites to be effective; therefore, the ability for elevated local production of BMPs by the patient may be advantageous and could be achieved through gene transfection (Nakashima, 1994a; Nakashima and Reddi, 2003).

\section{Purpose and Scope}

The purpose of the present review was to explore the literature surrounding extracellular bioactive molecules known to be sequestered in dentine (Austah et al., 2019; Goldberg et al., 2011; Schmalz et al., 2017; Smith et al., 2012; Smith et al., 2016; Tomson et al., 2017) and summarise current evidence for their utility as PCAs.

It is pertinent in biomaterial engineering to consider the delivery mechanism (or carrier) when considering delivery of any molecules, because spatiotemporal control over the release of bioactive molecules controls the resulting tissue regeneration (Rambhia and Ma, 2015). However, extensive coverage of carriers for pulp capping is beyond the scope of the present review.

For all molecules discussed, the study focused on literature published in the English language, with a preference for best and most recent evidence for the use of each molecule, namely in vivo studies over in vitro work, where available, and focused on studies specifically addressing pulp capping. However, there is a general lack of large-scale works in this field, with most publications being small-scale singular animal or in vitro studies. Hence, the present review attempted to accumulate the most pertinent works on each molecule and evaluate current evidence for its utility within a PCA.

\section{Extracellular bioactive molecules known to be sequestered in dentine}

\section{Anabolic/dentineogenic and mitogenic molecules} TGF- $\beta$

TGF- $\beta$ s (isoforms TGF- $\beta 1$, TGF- $\beta 2$ and TGF- $\beta 3$ ) are multifunctional cytokines secreted following an initial inflammatory response, are potent modulators of tissue repair and are expressed by all cells in the human body (Niwa et al., 2018; Vander Ark et al., 2018). TGF- $\beta$ s at the cellular level regulate proliferation, migration, differentiation as well as apoptosis and, more generally, they play a role in regulation of inflammatory responses and both tumour suppression and progression (Vander Ark et al., 2018). Factors such as $\mathrm{pH}$, integrins and various proteases (e.g. MMP2, MMP9, plasmin) activate TGF- $\beta$ s (Niwa et al., 2018). TGF- $\beta 1$, TGF- $\beta 2$ and TGF- $\beta 3$ are receptor ligands which bind to TGF- $\beta$ receptors (TGF- $\beta$ receptor 1 , TGF- $\beta$ receptor 2 and TGF- $\beta$ receptor 3) (Vander Ark et al., 2018), with TGF- $\beta 1$ being the predominant isoform (Niwa et al., 2018). Within pulpal inflammation, TGF- $\beta 1$ is involved in chemotaxis of inflammatory cells, angiogenesis, deposition of ECM and formation of new tissue (About et al., 2000a). In addition, it plays a role in odontoblast differentiation (Begue-Kirn et al., 1992; Nakashima, 1992). Within the pulp, TGF- $\beta 1$ is activated through degradation of the TGF- $\beta 1$ complex, leading to elevated DSPP and MMP20 levels (Niwa et al., 2018).

TGF- $\beta 1$ interacts with the ECM in a unique way. It is secreted as a homodimer, non-covalently attached to LAP. When bound to LAP, TGF- $\beta 1$ is prevented from attaching to cell receptors [and is therefore latent (TGF- $\beta 1$-LAP)]. TGF- $\beta 1-L A P$ is bound and stored in the ECM through LTBP-1. Mechanical forces within the ECM (from actin and myosin cellular contractions) are transmitted to a binding site present on LAP, which induces a hypothetical conformation change, liberating the bound TGF- $\beta 1$. In essence, a pulling mechanism from a cellularbound integrin releases TGF- $\beta 1$ from the ECM-bound TGF- $\beta 1$-LAP. Application of a force to TGF- $\beta 1$-LAP without a mechanical anchor (provided by the LTBP1 binding to the ECM) would result in dragging/ translocation of the complex and no conformational change facilitating the release of TGF- $\beta 1$ (Hinz, 2015). This storage and release mechanism from the ECM produces a disjoint between secretion time and action time of TGF- $\beta 1$ (Hinz, 2015).

There are numerous in vitro studies demonstrating the ability of TGF- $\beta 1$ for inducing odontogenic differentiation of isolated DPSCs (Begue-Kirn et al., 1992; 1994). However, the present review focused on the potential of bioactive molecules being used as pulp-capping agents and, currently, only one human in vivo study has been performed on this subject (Kunarti, 2008). Therefore, most of the current best evidence for the use of TGF- $\beta 1$ as a bioactive molecule comes from in vivo animal models. The evidence for use of TGF- $\beta$ s as a bioactive molecule for pulp capping are discussed below.

In the only in vivo human study, Kunarti (2008) demonstrated that TGF- $\beta 1$ loaded onto collagen membranes $(20 \mathrm{ng} / \mathrm{mL}, 5 \mu \mathrm{L})$ can act as a suitable pulp-capping agent, producing similar effects to $\mathrm{Ca}(\mathrm{OH})_{2}$ but with earlier induction of angiogenesis. However, this study used sound premolars scheduled for extraction due to orthodontic reasons, with a follow up of only $21 \mathrm{~d}$, making the comparison to routine clinical use (i.e. a carious tooth with a longterm restoration) difficult; although, the initial results appeared promising (Kunarti, 2008). 
In a dog model, Li et al. (2014) used a chitosan bilayer membrane, containing TGF- $\beta 1$-loaded chitosan microspheres, and compared the effectiveness of this loaded biomaterial for pulp capping to an unloaded chitosan scaffold, no pulp cap and $\mathrm{Ca}(\mathrm{OH})_{2}$. They found that all agents and the control group induced an initial inflammatory response, but only the $\mathrm{Ca}(\mathrm{OH})_{2}$ and loaded chitosan groups produced reparative dentine - and of these, the loaded chitosan scaffold produced 3-6 times more reparative dentine than $\mathrm{Ca}(\mathrm{OH})_{2}$. In an earlier dog model study by Tziafas et al. (1998), TGF- $\beta 1$-loaded filters formed odontoblasts and dentine and were more successful than FGF and IGF in producing dentine. Similar findings were also identified by Zhang et al. (2008) using a goat model with TGF- $\beta 1$ loaded onto poly(lactic-co-glycolic acid) microspheres used for pulp capping. They found that a higher concentration of TGF- $\beta 1(400 \mathrm{ng})$ formed a better tertiary dentine bridge than a lower concentration (20 ng); none of the negative controls produced dentine (Zhang et al., 2008). Conversely, in a rat study by Oliva-Rodríguez et al. (2011), TGF- $\beta 1$ loaded onto alginate microparticles, specifically designed for controlled release, produced a similar result to $\mathrm{Ca}(\mathrm{OH})_{2}$ for pulp capping. However, with the addition of BMP-7 to the TGF- $\beta 1$-loaded alginate, the effects were improved (Oliva-Rodríguez et al., 2011).

When comparing TGF- $\beta 1$ to other bioactive molecules, TGF- $\beta 1$ has been shown to outperform BMP-7 and WNT-1. In a porcine-model study, a $\mathrm{Ca}_{2} \mathrm{SiO}_{4}$-based material was soaked in a solution containing BMP-7, TGF- $\beta 1$ or WNT-1 and each bioactive molecule was assessed for pulp capping. Each calcium silicate scaffold was soaked in $30 \mu \mathrm{L}$ of a $300 \mathrm{mg} / \mathrm{mL}$ porcine albumin solution containing $30 \mathrm{mg}$ of the bioactive molecule. TGF- $\beta 1$ induced odontoblastic differentiation and a more consistent reactive dentine formation of an appropriate depth and structure for effective pulp capping (Tziafas et al., 2017). Hu et al. (1998) also showed that TGF- $\beta 1$ loaded onto a collagen scaffold can outperform PDGF-BB, FGF, EGF, IGF and $\mathrm{Ca}(\mathrm{OH})_{2}$ in a rat animal model. In contrast to the studies supporting the use of TGF- $\beta 1$, Nakashima (1994a) reported no dentine formation and impaired pulpal healing with TGF- $\beta 1$ $(2 \mu \mathrm{g})$ loaded onto collagen and implanted into a dog model.

Based upon these studies, it is possible that the release frequency and nature of the carrier may have an effect on the activity of TGF- $\beta 1$ in inducing tertiary dentineogenesis and reparative pulpal changes. However, it is also clear that TGF- $\beta 1$ may be as good, if not better than $\mathrm{Ca}(\mathrm{OH})_{2}$ as a PCA. Modification of the delivery mechanism to incorporate synergistic growth factors could be promising for improved results. The wealth of literature supporting TGF- $\beta 1$ makes it a front-runner for inclusion in a biomimetic PCA, despite it being more than 10 years since the in vivo human study. It is not clear why exploration of this bioactive molecule for use as a PCA has slowed down when it shows such promise. Further clinical trials are needed to move forward the research on this growth factor.

\section{$B M P S$}

Morphogens are extracellularly secreted signals governing morphogenesis and controlling craniofacial patterning. Morphogens are divided into four evolutionarily conserved protein families: BMPs, FGFs, hedgehog proteins and WNT-related proteins (Nakashima and Reddi, 2003). BMPs are a family of 22 secreted ECM-associated proteins involved in numerous functions within the human body, such as muscle development, stem cell and organ formation, bone and cartilage formation, iron metabolism and vascular biology (Brazil et al., 2015; Nakashima and Reddi, 2003). BMPs are considered part of the TGF- $\beta$ family, with both acting on Smad intracellular signalling (TGF- $\beta$ utilising Smad1/5/8, BMPs utilising Smad2/3) (Brazil et al., 2015; Nakashima and Reddi, 2003).

BMPs have been added to scaffolds as DNA (gene therapy) or proteins for dentineogenic pulp capping. BMPs have a short half-life and are required in high concentrations at the local site to be effective; therefore, the ability for local elevated production of BMP proteins by the patient may be advantageous and could be achieved by gene transfection (Nakashima, 1994a; Nakashima and Reddi, 2003). An example of BMP use for gene therapy can be found in the study by Yang et al. (2009), who used an adenoviral vector containing human BMP-2 transfected into DPSCs and loaded onto a sintered ceramic scaffold. In vitro and in vivo experiments demonstrated mineralised tissue formation but with an appearance more similar to bone than to dentine. To explain the formation of bone over dentine, the authors suggested that BMP-7 may be a more appropriate candidate for dentine production and that the scaffold structure and environment (at a micro and macro level) may play a role in the formation of bone over dentine from cells of dental pulp origin. Subsequently, BMP-7 carried on nanofibrous poly(L-lactic acid) scaffolds has been used successfully in vitro and in vivo to push odontoblastic differentiation and dentine-like hard tissue formation (Wang et al., 2010).

Similarly to TGF- $\beta 1$, there is a wealth of literature confirming the role of BMPs in dentineogenesis and their ability to induce odontogenic differentiation (About et al., 2000b; Chen et al., 2008; Iohara et al., 2004; Suzuki et al., 2011), with BMP2 and BMP7 being the most explored. However, there are considerably fewer studies covering the use of BMPs specifically as pulp-capping agents for in vivo applications (except for animal models) and no clinical trials have been conducted on this topic. Some of the earliest work on BMPs for pulp capping was carried out by Nakashima (1994b; 1994a), who explored BMPs for pulp capping in a dog model. Briefly, across two studies, the authors explored the use of recombinant BMP-2 and BMP-4 carried on a collagen matrix 
(Nakashima, 1994a) and mixed with inactivated, demineralised dentine matrix powder (particle size 200-500 $\mu \mathrm{m}$ size) (Nakashima, 1994b). When used in conjunction with collagen, BMP-2 (2 $\mu \mathrm{g})$ and BMP-4 (4 $\mu \mathrm{g})$ induced osteodentine formation; however, tubular dentine was lacking and, interestingly, the unloaded collagen carrier control produced a very minimal amount of osteodentine (Nakashima, 1994a). When used in conjunction with inactive, demineralised powered dentine, $2 \mu \mathrm{g}$ of BMP-2 and $\mathrm{BMP}-4$ induced osteodentine formation towards the superficial side of the cavities and tubular dentine towards the deeper radicular part (Nakashima, 1994b).

BMP-2 has been explored as a pulp-capping agent in conjunction with MTA. $1 \mathrm{~g}$ MTA mixed with $1 \mu \mathrm{g}$ BMP-2 was compared to MTA alone and no difference in the quality and quantity of reparative dentine was seen between rat groups. In addition, in both groups, the reparative dentine had a bone-like morphology (Ko et al., 2010). When BMP-7 was compared to MTA as a pulp-capping agent in rats, MTA outperformed BMP-7, with a more impervious dentine bridge being formed in the MTA group and increased DSP activity. In addition, the material produced by BMP-7 resembled bone more than dentine (Andelin et al., 2003). However, BMP-7 was added to the pulp without the adjunct of a scaffold, highlighting the potential importance of the scaffold in BMP delivery (probably for timely and sustained release) and potentially structural direction in influencing tubular dentine deposition over osteodentine.

For pulp capping, BMP-7 and BSP (each delivered on a gelatine carrier) have been shown to produce more mineralised tissue than $\mathrm{Ca}(\mathrm{OH})_{2}$ in a rat model (Goldberg et al., 2001). The BMP-7 group produced more tissue towards the apical and radicular areas of the pulp, whereas the BSP group produced dentine more in the coronal area. The dentine produced by the BSP group was more tubular and less pervious than the one produced by the BMP-7 group (Goldberg et al., 2001). The preferential production of osteodentine in the radicular area of the pulp was also found by Six et al. (2002b) exploring BMP-7 on collagen scaffolds as pulp caps.

Rutherford et al. $(1993 ; 1994)$ explored the use of BMP-7 using primate animal models. Using a powdered collagen matrix mixed with recombinant human BMP-7 (2.5 $\mathrm{gg} / \mathrm{mg}$ of collagen), they compared BMP-7 to $\mathrm{Ca}(\mathrm{OH})_{2}$ (Rutherford et al., 1993) and explored tertiary dentine formation at different time points (Rutherford et al., 1994). In summary, BMP-7 outperformed $\mathrm{Ca}(\mathrm{OH})_{2}$ in the short term (Rutherford et al., 1993) and demonstrated $75 \%$ tertiary dentine bridge formation at 1 month and $95 \%$ at 4 months (Rutherford et al., 1994). Similar to other studies, the unloaded collagen carrier failed to produce a dentine bridge, with the dentine produced being a mix of tubular dentine and osteodentine.

More recent studies have attempted to discover the optimum dosage of unloaded BMP-7 to push odontogenic differentiation in culture and maintain DPSC proliferation: $50 \mathrm{ng} / \mathrm{mL}$ and $100 \mathrm{ng} / \mathrm{mL}$ were the most successful (Zhu et al., 2018).

One issue with many of these studies is that sterile, uninflamed teeth were used. This is an issue that Rutherford and Gu (2000) attempted to resolve by exploring BMP-7 delivered on collagen scaffolds to inflamed ferret pulps. The results showed no reparative dentineogenesis, possibly in relation to elevated BMP antagonistic binding proteins present in inflamed dental pulps inactivating the protein. Rutherford (2001) went on to explore whether in vivo gene transfection of BMP-7 in an adenovirus within a collagen hydrogel carrier could induce reparative dentine formation in inflamed ferret pulps and compared this to autologous fibroblasts transfected with BMP-7 ex vivo, also carried in a collagen hydrogel into the inflamed pulps. The direct transfection group did not produce reparative dentine; however, the group with pulps capped using the ex vivo transfected fibroblasts did produce good quality reparative dentine with associated odontoblasts. The authors postulated that this may be due to sustained secretion by the fibroblasts of BMP-7.

Recombinant BMP-2 is marketed commercially for bone regeneration (InductOs ${ }^{\mathrm{TM}}$, Medtronic BioPharma, Herleen, the Netherlands) similarly to recombinant BMP-7 (Osigraft ${ }^{\mathrm{TM}}$, Olympus Biotech, Limerick, Ireland). However, both of these systems have variable success rates and little long-term clinical evidence supporting their use (Ayoub and Gillgrass, 2019; Calori et al., 2015; Chevet-Noël et al., 2020; Corinaldesi et al., 2013; Sailhan et al., 2010; Vincentelli et al., 2019). No research has been undertaken using these materials off-label for dental-pulp capping, although the systems used are similar to the experimental work carried out using recombinant BMP-2 and BMP-7 and this could be a specific area of interest moving forwards.

Blended scaffolds have also been used to successfully deliver plasmid vectors coding for BMP7. In the study by Yang et al. (2012), chitosan/collagen scaffolds (one containing a plasmid coding for human BMP-7 and one control) were seeded with DPSCs and implanted subcutaneously in mice. They were reviewed after 4 weeks and upregulation of DSPP was observed (suggesting odontoblastic differentiation) in both groups, with a significantly higher upregulation in the BMP-7 group.

In summary, BMP-2 and BMP-7 have been used with varying degrees of success as pulp-capping agents in animal studies. Although, a bone phenotype may result in hard tissue produced and this seems to occur more when the BMP is not delivered on a scaffold. This is not ideal for pulp capping as bone is more porous than dentine and can therefore be pervious, preventing a suitable pulp seal. It is not currently known what causes a bone phenotype over a dentine phenotype; the carrier, the environment, the use of proteins or DNA may all play a role and further work is needed to resolve this issue should BMPs 
be pursued as a potential pulp-capping bioactive molecule. The limitation of a high concentration of BMPs required to produce dentine, the possibility of inflammation impeding their action and the short half-life of these molecules are significant hurdles. Although there is considerable literature exploring BMPs as PCAs and clinical application of these molecules has reached the commercial market for bone regeneration, dentine is not the same as bone and until the issue of bone production over dentine production is resolved and controlled BMPs may prove less suitable for PCAs than TGF- $\beta 1$ and other molecules (discussed below) may show more promise.

\section{IGF}

The IGF system is complex, being comprised of 2 ligands (IGF-2 and IGF-2), 2 cell surface receptors, at least 6 IGFBP and multiple proteases (Catón et al., 2007). IGF-1 is covered most widely in the literature. It is a cell surface receptor tyrosine kinase that binds to IGF-1 and IGF-2 receptors to activate various downstream signalling pathways, such as AKT/ protein kinase B (a signal transduction pathway) and MAPK (Teng et al., 2018). IGF-1 has been implicated in the differentiation and proliferation of DPSCs along the odontogenic and osteogenic lineages (via the MAPK pathway) (Lv et al., 2016; Nakashima, 1992). It also plays a role in tertiary dentine formation: a mouse study by Matsumura et al. (2017) showed that tertiary dentine volume was reduced following odontoblast-specific IGF-1 ablation. IGF-1 signalling is also implicated in cell stemness, including cancer cell stemness, and resistance to chemotherapy, which has raised concerns over its use (Teng et al., 2018).

Limited in vivo work has been completed to explore the use of IGF-1 as a bioactive molecule in pulp capping. In a rat study (Lovschall et al., 2001), the efficacy of IGF-1 as a potential pulp-capping bioactive molecule was proven: recombinant IGF-1 (400 ng) was loaded onto methylcellulose gels and compared to methylcellulose gels loaded with saline and $\mathrm{Ca}(\mathrm{OH})_{2}$. In all the teeth examined histologically, dentine bridges covered more than $50 \%$ of the pulp; however, significantly more tertiary dentine was identified in the IGF-1-loaded group.

When looking at IGF-2 for pulp capping in a rat model, Hu et al. (1998) found only fibrous tissue after IGF-2 treatment and, by comparison, TGF- $\beta 1$ proved to be more effective for pulp capping.

With little experimental animal data, IGF-1 and IGF-2 need considerably more evidence for their efficacy before considering them as a potential bioactive molecule for pulp capping. As very little work has been done on IGF-1 for pulp capping, it seems this bioactive molecule has largely been sidelined in favour of other molecules, such as TGF- $\beta 1$. Concerns over carcinogenesis may be limiting the exploration of this growth factor for use as a pulpcapping agent.

\section{FGF-2}

There is limited literature surrounding the use of FGF-2 for pulp capping, despite FGF-2 being implicated as a potential bioactive molecule in DPSC differentiation (Nakashima, 1992) and its proven role in tertiary dentineogenesis (Hu et al., 1998) (although admittedly to a lesser extent than TGF- $\beta 1$ ). FGF-2 is known to be a promoter of stem cell homing, stemness, proliferation and angiogenesis (Lim et al., 2017; Smith et al., 2016).

One in vivo study exploring FGF-2 role in tertiary dentineogenesis was performed by Kikuchi et al. (2007), where collagen sponges mixed with FGF2-loaded gelatine hydrogels were implanted into the exposed upper molars of rats. This provided a controlled release of FGF-2 and was compared to pulps capped with free FGF-2 and the collagen sponge/gelatine hydrogel mixture alone. The free FGF-2 group demonstrated tertiary dentine formation only in the residual pulp, whereas with controlled release of FGF-2, the tertiary dentine formation was all over the pulpal exposure. This demonstrated that the controlled release of FGF-2 is pertinent to the formation of dentine in a pulp cap. In a later work by Ishimatsu et al. (2009), different concentrations of FGF-2 were explored as PCAs loaded in their collagen sponge/gelatine hydrogel carrier and implanted into exposed rat pulps: DPSCs and vessels invaded the scaffold and dentine was produced. A concentration of $0.5 \mathrm{mg} / \mathrm{mL}$ of FGF-2 was found to produce the largest volume of tertiary dentine (Ishimatsu et al., 2009).

FGF-2 (like many of the bioactive molecules sequestered in dentine) has been more widely explored for bone regenerative purposes and proved to be successful in animal models (e.g. Behr et al., 2012; Hong et al., 2010; Kigami et al., 2013). Therefore, it is probably only a matter of time before exploration of FGF-2 becomes more common in the field of pulp capping and the limited current evidence is very encouraging. It does seem that controlled release of this molecule is key to its efficacy in sealing the pulp, so careful consideration of the scaffold to use for transporting FGF-2 into the tissue as well as releasing it into the pulp is required.

\section{EGF}

EGF is part of an EGF family of ligands and was first isolated from mouse salivary glands. When bound to their high-affinity receptors, these ligands have powerful mitogenic activities. Following binding, EGF activates two major intracellular pathways that induce cell proliferation and cytoprotection (Berlanga-Acosta et al., 2009) and it is implicated in DPSC migration (Howard et al., 2010). Although important for tissue repair and regeneration, EGF is also implicated in tumour progression ( $\mathrm{Xu}$ et al., 2017).

Very little work has been done to explore EGF's role in dental-pulp capping - possibly (similar to 
IGF-1) due to its known links to tumour progression. Most of the research on EGF for pulp capping is over 20 years old. As an example, Hu et al. (1997) studied the effects of PDGF (5 ng/ $\mu \mathrm{L})$ and EGF $(2 \mathrm{ng} / \mu \mathrm{L})$ soaked onto a collagen membrane and inserted into an exposed rat incisor. They found a combination of PDGF-BB and EGF to outperform $\mathrm{Ca}(\mathrm{OH})_{2}$ and the unloaded collagen membrane (Hu et al., 1997). Hu et al. (1998) went on to explore EGF, again on collagen membranes in a rat model, in comparison to other bioactive molecules (TGF- $\beta 1$, PDGF-BB, IGF-2, FGF) and compared it to the unloaded collagen carrier and $\mathrm{Ca}(\mathrm{OH})_{2}$. TGF- $\beta 1$ was the best at producing a dentine bridge with a tubular quality and limited pulpal inflammation. However, the authors noted that the other molecules may have therapeutic utility when used in unison (Hu et al., 1998), although this requires further exploration.

The fact that other bioactive molecules have been shown to outperform EGF limits the exploration of this molecule as a sole agent in pulp capping. However, its utility as a powerful mitogen, ability to increase cell proliferation and role in cytoprotection may prove incredibly valuable in the typically inflamed environment where pulp caps are used. For these reasons it may be beneficial to consider EGF as an adjunct in PCAs, to be used with more established molecules such as TGF- $\beta 1$.

\section{Angiogenic molecules}

\section{VEGF}

The role of VEGF in pulp regeneration has been widely explored for potential revascularisation of the pulp tissue (Al-Hassiny et al., 2019; Zhang et al., 2011), due to its angiogenic properties. However, little work has been done covering the use of this bioactive molecule for pulp capping. For successful dental dental-pulp capping, a hard dentine bridge is required. VEGF, when bound to its receptor, has several functions; it stimulates endothelial cell proliferation, increases blood flow, facilitates chemotaxis, and increases capillary hyperpermeability (Al-Hassiny et al., 2019; Matsushita et al., 2000). It has a comparatively short half-life (Zhang et al., 2014), is expressed throughout the DPC in both mature and immature teeth and affects mineralisation and odontoblastic differentiation in the early stages of DPSC differentiation (Aksel and Huang, 2017). In vitro, it can induce odontoblastic differentiation of DPSCs through gene transfection (Zhang et al., 2014), demonstrating its potential use as a PCA. VEGF's short half-life means that, without gene transfection, VEGF recombinant protein will require a carrier for sustained release. A chitosan $/ \beta$ glycerophosphate scaffold carrying $100 \mathrm{ng} / \mathrm{mL}$ of VEGF protein was used successfully in vitro to achieve odontoblastic differentiation of DPSCs; moreover, the use of the carrier facilitated controlled release with better mineralisation than VEGF alone $(\mathrm{Wu}$ et al., 2019).

Much of the work on VEGF for pulp capping has only been accomplished in the last 5 years, possibly due to dental researchers focusing solely on its angiogenic role (as implied by its name) and failing to consider the other roles this bioactive molecule may have. To date, no in vivo studies have been carried out to explore VEGF as a PCA. Its short half-life means that controlled and sustained release may be necessary to have any significant effect. Its role in odontoblastic differentiation warrants further exploration.

\section{HGF}

It has long been established that pulpitis increases HGF expression in the dental pulp (Ohnishi et al., 2000; Ohnishi and Daikuhara, 2003), that HGF is a potent mitogen and morphogen and that HGF has angiogenic and cellular motility effects (Ye et al., 2006). In vitro work has also demonstrated that HGF can increase DPSC proliferation and odontoblastic differentiation (Ye et al., 2006). As HGF is also released from dentine matrix, it is thought to contribute to cellular signalling events in DPC repair (Tomson et al., 2013). FGF-2 is thought to stimulate the secretion of both HGF and VEGF, leading to an increase in angiogenesis (Gorin et al., 2016) in the dental pulp. As HGF has demonstrated multiple roles in vitro in the healing of the DPC, it could be a powerful additive to a biomimetic PCA. To date HGF has not been explored as a PCA in vivo - it will be interesting to see how the knowledge on this peptide and its role in tertiary dentineogenesis increases with time, although the initial work completed on this molecule is promising.

\section{PDGF}

PDGF stimulates pulp cells and pushes their differentiation into odontoblasts (Nakashima, 1992; Zhang et al., 2017b). PDGF is present in dentine matrix (Roberts-Clark and Smith, 2000) and consists of a family of 5 polypeptides (PDGF-AA, PDGF-AB, PDGF-BB, PDGF-CC, PDGF-DD), with PDGF-BB being the most widely explored as it interacts with all three PDGF receptors (Zhang et al., 2017b). PDGF is known to be a powerful mitogen, with potent angiogenic effects, and it is a key mediator in wound healing and tissue regeneration (Zhang et al., 2017b). It is also known to be a powerful chemoattractive agent for mesenchymal stem cells and DPSCs (Zhang et al., 2017b). Positive synergistic effects have been noted in vitro between PDGF and TGF- $\beta 1$ as well as dentine non-collagneous proteins, leading to increased cell viability and proliferation when compared to each of these factors alone (Tabatabaei and Torshabi, 2016).

PDGF-BB can stimulate tertiary dentineogenesis, although not as much as TGF- $\beta 1$ (Hu et al., 1998), possibly limiting further exploration of this molecule. Similar to HGF, the multiple roles this molecule likely plays in the healing of the DPC necessitates a better understanding of its potential therapeutic role in dentistry. More in vivo work is needed to establish the role of PDGF in dentineogenesis for pulp capping, although it seems that this peptide most likely plays a 
synergistic role in a biomimetic PCA, likely coupled with another molecule.

\section{PlGF}

PIGF present in dental matrix (Roberts-Clark and Smith, 2000) is thought to play a role in osteoblastic differentiation (McCoy et al., 2013) and angiogenesis (Kinnaird et al., 2004). It has not been fully explored to elucidate its role in tertiary dentineogenesis and no in vivo work has been accomplished. Because of this, it is currently very difficult to see what role PIGF may have in a biomimetic PCA and it is included in the present review only as a matter of completeness.

\section{Inflammatory cytokines \\ ILs}

Inflammatory cytokines are present in dentine components sequestered in pulp caps and caries. They also have a reparative role in low-grade inflammatory processes (such as those induced by dental injury), contributing to DPC repair (Tomson et al., 2017). IL-1 $\alpha$, IL-1 $\beta$, IL-4, IL-6, IL-8 and IL-12 are sequestered in dentine, with IL- 8 being the most abundantly expressed (Cooper et al., 2010).

ILs are secreted proteins, capable of binding to specific receptors, that play a role in the communication among leukocytes (Akdis et al., 2011). Although ILs are traditionally considered to be inflammatory molecules, they are present in dentine and their associated inflammatory response is widely considered an integral part of the regenerative process of dental-pulp capping (Cooper et al., 2010; Smith et al., 2012). Careful modulation and resolution of the inflammatory process is key to facilitate regeneration (Smith et al., 2012). The balance between mild inflammation, facilitating the eradication of carious bacteria and their toxins, and tissue regeneration is delicate and complex. If the inflammatory response is too strong, the tooth will lose vascularity and become necrotic; if it is too weak, deleterious stimuli will remain, leading to increased tissue damage. It is perhaps because of this refined interplay between inflammation and regeneration that ILs have not been widely explored in the literature as a potential bioactive molecule to add to a PCA. As exogenous ILs may add to and affect the balance between inflammation and regeneration, it would be better to avoid their usage as additives to PCAs until the therapeutic levels of these proteins will be better understood.

\section{Colony-stimulating factors (GM-CSF and G-CSF)}

GM-CSF and G-CSF are members of the colonystimulating factor group of glycoproteins and are known to be present in the inflamed pulp (Tomson et al., 2017). They stimulate the senescence, proliferation and differentiation of haematopoietic cells (Nakashima and Iohara, 2017; Trapnell and Abe, 2006).

The secretion of GM-CSF (and osteopontin) by immunocompetent cells at the dentine-pulp junction induces local maturation of dendritic cells, thus encouraging increased activity of odontoblasts and their differentiation from pulpal resident progenitors, causing speculation over the potential role of GM-CSF in odontoblastic differentiation (Saito et al., 2011). G-CSF is effective at mobilising DPSCs (Nakashima and Iohara, 2017), which is essential for the replacement of apoptosed odontoblasts at the dentine-pulp junction, necessary for tertiary dentineogenesis.

G-CSF with autologous isolated DPSCs, on a collagen scaffold, is capable of regenerating a DPC in a dog model. For this study, numerous control groups were used, although unfortunately none with G-CSF alone, making it difficult to attribute the regeneration solely to G-CSF (Iohara et al., 2013). G-CSF is also beneficial to inducing mineralisation for dentineogenesis in vitro (Takeuchi et al., 2015).

Little work has been done to explore the roles that GM-CSF and G-CSF may play in in vivo pulp capping and the potential that harnessing these bioactive molecules may have in aiding DPSC recruitment (possibly even to a suitable acellular scaffold that is capable of being colonised) and differentiation for reparative dentineogenesis. Although both molecules are currently used therapeutically to treat haematological malignancies, more in vitro and animal work is required before they can be considered suitable for human clinical trials for pulp capping. Until the potential role of these molecules in biomineralisation is better understood, it is unlikely that they would be used as sole agents in any PCA.

\section{$I g$}

Igs, also known as antibodies, are Y-shaped glycoproteins predominantly produced by plasma cells. IgA, IgG and IgM are believed to be sequestered in dentine (Schmalz et al., 2017) and, likely, they play a role in the defence against cariogenic bacteria (Smith et al., 2012). The role of Igs in production of a hard tissue dentine bridge is entirely speculative, with no evidential support (Smith et al., 2012), making the case for their inclusion in an experimental PCA difficult. Nevertheless, their role in combatting any residual caries would prove beneficial in a PCA, if an alternative more broad-spectrum anti-microbial was not included. They are included in this review only for completeness.

\section{Chemotactic \\ SCF}

SCF is a chemokine as well as homing agent for progenitor-cell recruitment and can cause a significant increase in DPSC proliferation (Pan et al., 2013). Moreover, it has a potential role in the differentiation of DPSCs towards odontoblasts (Ruangsawasdi et al., 2017). SCF is known to be released from dentine during pulp capping (Tomson et al., 2017). No in vivo pulp-capping experiments have been published so far and most of the current knowledge on SCF has been gained in the last 5 
years. Exploration and potential exploitation of this bioactive molecule for DPC regeneration is still very much in its infancy and without any evidence supporting its direct role in hard-tissue barrier formation, it is likely that SCF would only have a supportive role in DPC regeneration from a PCA. Due to the lack of information surrounding this molecule for dental-pulp capping, it is included in the present review only for completeness.

\section{Neurotrophic proteins}

Neuropeptides have been identified in dental ECM and are thought to play various roles in pain transduction (Smith et al., 2012). Neuropeptides are associated with pulp regeneration, neural differentiation and angiogenic events (Li and Wang, 2016; Smith et al., 2016; Zhang et al., 2017a) but specifically tertiary dentineogenesis and pulp capping are less widely explored. NGF, GDNF, neurotrophin 3, neurotrophin $4 / 5$ and BDNF are known to be sequestered in the dentine, with GDNF and neurotrophin 4/5 being the most expressed (Austah et al., 2019; Tomson et al., 2017). The role these molecules may play in pulp capping is poorly understood and is an area of recent exploration (Austah et al., 2019). No in vivo work has been completed exploring the role of neurotrophic proteins as part of a pulp-capping system, although GDNF, BDNF and neurotrophin $4 / 5$ are thought to affect DPSC migration (Xiao et al., 2018; Xiao et al., 2020). NGF has been shown to play a potential role in differentiation of odontoblasts (Arany et al., 2009; da Rosa et al., 2018a), thereby facilitating dentineogenesis; although no in vivo work has been done to confirm this result. Evidence supporting the use of neurotrophic proteins in an experimental PCA is too weak for them to be considered as a viable option. It is likely that these molecules play a role in the inflammatory pulpal response but there is no evidence that they directly assist with hard-tissue barrier formation in the pulp. With further work exploring their actions in vitro, and eventually in vivo, they may prove useful as an additive to assist in odontoblastic differentiation but it is difficult to see how they could play a role as sole agents in a PCA.

\section{SIBLINGS}

After collagen, SIBLINGs are the most abundant peptides in dentine. They are capable of binding to integrin receptors, facilitating cell attachment and signalling. The SIBLING family includes OPN, BSP, DMP1, DSPP and MEPE (Bleicher et al., 2015). Members of the SIBLING family are often used as markers for odontoblast differentiation, although it is important to note that their expression can overlap with osteoblasts and be associated with bone (Smith et al., 2012).

DMP-1 can induce odontoblastic differentiation of DPSCs and stimulate mineralised tissue deposition (Hao et al., 2002; He et al., 2003; Narayanan et al., 2001). DMP-1 is also thought to play a role in activating pulpal fibroblasts as part of the inflammatory- regenerative process following pulpal damage (AbdElmeguid et al., 2012). Work has been performed to explore its use for endodontic perforation repair (Alsanea et al., 2011), finding a collagen scaffold loaded with DPSCs and DMP-1 to be capable of repairing a perforation with newly deposited dentine. DMP-1 has been hypothesised to be cleaved by MMP-2 into two forms, with the C-polypeptide form influencing the differentiation of DPSCs towards odontoblasts. The same researchers went on to explore the use of this cleaved form of DMP-1 for pulp capping when loaded onto agarose beads in a rat model and finding that the cleaved DMP-1 produced a dentine bridge faster than unloaded agarose beads and of a higher quality (Chaussain et al., 2009).

DSPP is immediately cleaved following production into DSP and DPP (Bleicher et al., 2015; Smith et al., 2012). DSP plays a role in DPSC differentiation and hard-tissue formation ( $\mathrm{Li}$ et al., 2017). Moreover, it is involved in migration and activation of immune cells (da Rosa et al., 2018a). DPP is involved in mineralisation and plays a role in the initial formation of hydroxyapatite crystals (da Rosa et al., 2018a). Very few in vivo studies focused on exploring the effects of DSPP, DSP or DPP as PCAs. One of these few studies explored the use of a DSP synthetic peptide as a PCA in a dog model (Kim et al., 2009) and compared this to MTA and $\mathrm{Ca}(\mathrm{OH})_{2}$. The study found more inflammation and less hard-tissue deposition in the synthetic DSP group compared to both the MTA and $\mathrm{Ca}(\mathrm{OH})_{2}$ groups, which both had similar results. In a study exploring DPP crosslinked to the fibrils of a collagen scaffold $(0.5 \mu \mathrm{g}$ of DPP and $29.5 \mu \mathrm{g}$ type I atelocollagen fibrils) in a rat model, better quality reparative dentine was found in the experimental group than in the collagen alone and $\mathrm{Ca}(\mathrm{OH})_{2}$ control groups (for example, a lack of tunnel defects and more complete coverage of the pulp) (Koike et al., 2014). Koike et al. (2014) also found the rate of dentine deposition to be faster in the experimental group than in the control groups. Because the DSP synthetic peptide performed so badly compared to other PCAs, it is probably not a key molecule to pursue in the design of a biomimetic PCA. However, DPP results are encouraging and it may be that out of the two molecules cleaved from DSPP, DPP is the more pertinent for tertiary dentine formation. Further work needs to be performed exploring DSPP and its products to better understand the roles they play in dentine-bridge formation and DPC repair.

BSP is expressed in tertiary dentine and, similar to DPP, is involved in the initial formation of hydroxyapatite; although, following initial production, it can also act as an inhibitor (da Rosa et al., 2018a; Smith et al., 2012). Therefore, it may be better considered as a regulator of hydroxyapatite formation. Six et al. (2002a) compared the effects of BSP and BMP-7 (both within a gelatine carrier) for pulp capping, as previously discussed. BMP-7 predominantly elicited osteodentine deposition in the coronal and radicular areas of the pulp, leading to 
near total pulpal obliteration, whereas BSP produced a more atubular dentine, filling only a third of the crown. Like many of the SIBLINGs, the role of BSP in dentineogenesis has been explored to some degree, but very few studies have been completed assessing its potential role as a PCA. The work by Six et al. (2002a) raises the possibility that BSP may be a better bioactive molecule for inclusion in a PCA than BMP7 , partially due to its more controlled mineralisation effects and, also, due to a better, more impervious, hard-tissue barrier being formed. BSP may indeed be a key component for future PCAs and, as has been shown, can outperform the more commonly considered BMP group of molecules. This warrants further investigation.

OPN is another molecule poorly researched for pulp capping; although, this may be in part due to its perceived action of inhibiting hydroxyapatitecrystal growth (da Rosa et al., 2018a). However, OPN plays an essential role in the collagen formation of tertiary dentineogenesis from new odontoblastlike cells (Saito et al., 2016). Although inhibition of hydroxyapatite propagation may seem like the opposite effect to what is required for a PCA, careful and controlled moderation of dentine is essential for a successful clinical outcome - some PCAs [such as MTA (Agamy et al., 2004)] can cause pulpal obliteration from excessive dentine deposition, demonstrating a lack of hydroxyapatite inhibition. Further in vitro work is required to better understand the role OPN may play in tertiary dentineogenesis prior to consideration of this bioactive molecule as a PCA; although, it could be argued that the inhibitory role this molecule plays could be pivotal in controlling the dentine deposited.

The hypothesised functions of MEPE within tertiary dentineogenesis are primarily those of mineralisation regulation and inhibition as well as phosphate metabolism (Bleicher et al., 2015; da Rosa et al., 2018a). Six et al. (2007) rebuke the idea that MEPE inhibits mineralisation by exploring the actions of Dentonin, a synthetic derivative of MEPE, as a PCA when loaded onto agarose beads. Dentonin had a rapid action on the initial stages of pulpal repair (cell recruitment and cell proliferation). No evidence for mineralisation inhibition was detected in their rat model. As the exact role of MEPE in tertiary dentineogenesis is poorly understood, further work is needed to better understand the potential of this bioactive molecule as a PCA, although it is possible that it plays a regulatory role similar to the other SIBLING molecules.

\section{SLRPS}

SLRPs are a family of numerous proteoglycans, which can be subdivided into five classes: extracellular, pericellular (basement membrane zone), cell surface or intracellular, canonical and non-canonical (Listik et al., 2019). Five SLRPs have been identified in dentine matrix and predentine: decorin, biglycan, fibromodulin, lumican and osteoadherin (Orsini et al., 2009).

Decorin and biglycan have several hypothesised roles in dentineogenesis: i) collagen stabilisation, ii) collagen fibrillogenesis, iii) calcium binding, iv) hydroxyapatite interaction, v) hydroxyapatite growth inhibition (Orsini et al., 2009). Specifically, decorin and biglycan are believed to play a role in the organisation of the collagen matrix during dentineogenesis, to regulate other molecules such as TGF- $\beta 1$, to influence cell cycle progression and calcium binding (Baker et al., 2009; Embery et al., 2001). Fibromodulin, osteoadherin and lumican are believed to play roles in mineralisation of dental tissues (Orsini et al., 2009). Fibromodulin may also play a role in the fibrillogenesis of collagen in predentine (Goldberg et al., 2006). Fragmented SLRPs are also thought to potentially influence signalling to odontoblasts in tertiary dentine deposition (Stankoska et al., 2016).

To date, no experimental PCA studies have explored the use of SLRPs in in vivo models. Because their breakdown may help to signal to odontoblasts to begin dentine deposition, it may be beneficial to include fragmented versions of these proteoglycans in a PCA. However, as previous studies have shown that dentine deposition can be elicited without the inclusion of these molecules, they are not a priority for consideration. Further work on the roles of these molecules in dentineogenesis is required, including further clarification of their roles in carious and regenerative settings, before they can be considered as reasonable candidates for inclusion in a PCA.

\section{Other}

$A D M$

ADM is a protein cleaved and processed from preproadrenomedullin, is highly conserved across species and is part of the CGRP family (Musson et al., 2010).

$\mathrm{ADM}$ is thought to upregulate the expression of BMP-2, enhancing odontogenic differentiation of DPSCs (Zhu et al., 2017). This fits with the current understanding of the localisation of ADM to epithelial cells during initial dental development and, later, to mineralised secretory cells (including odontoblasts) (Musson et al., 2010). ADM has also been shown to be expressed at higher levels in carious compared to healthy extracted human teeth and to inhibit apoptosis and enhance proliferation of DPSCs in vitro (Zhu et al., 2016). ADM is thought to be involved in tertiary dentineogenesis, via p38, eliciting a process of odontoblastic differentiation and mimicking primary dentineogenesis (Simon et al., 2010); although, only in vitro work currently supports this hypothesis.

Few studies have explored the role of ADM in tertiary dentineogenesis. No human or animal studies were found in the literature exploring the use of this bioactive molecule as a PCA. Its ability to inhibit apoptosis in vitro could raise concerns over its use due to the link of immortal cells to tumour cell 
theorems. Indeed, the molecule was first identified in a pheochromocytoma (a tumour of adrenal glands) (Kitamura et al.,1993). Considering the current body of work covering ADM, it is not presently a candidate for use in a PCA, although further work eliciting the actions of this molecule in tertiary dentineogenesis may yield contradictory results.

\section{Calcitonin}

Calcitonin is a hypocalcaemic hormone. It was first explored as a pulp-capping agent in 1982 when Smith and Soni (1982) used a rat model for comparing pulp capping using $\mathrm{Ca}(\mathrm{OH})_{2}$ and calcitonin and discovered that calcitonin produced a similar response in terms of dentine deposition to $\mathrm{Ca}(\mathrm{OH})_{2}$. Similarly, in a dog model, Cullum and Kline (1985) found that although calcitonin was able to induce pulp-capping dentineogenesis, it did not outperform $\mathrm{Ca}(\mathrm{OH})_{2}$; although, less inflammation was identified in the calcitonin group. More recently, calcitonin has also been shown to stimulate osteodentine deposition in ferrets (Kline and $\mathrm{Yu}, 2009$ ), adding to the growing literature supporting this bioactive molecule as a potential candidate for inclusion in a biomimetic PCA. Since the early work on calcitonin, little progress has been made in exploring the best way of utilising this peptide in PCAs.

\section{Lipids}

No work has been done to date using lipids sequestered in dentine for pulp capping and these are included solely for completeness.

Lipids represent a small part of the dentine matrix (0.26-0.36 \%) (Goldberg et al., 2008b). Lipids found in dentine include phosphatidyl inositol, sphingomyelin, phospatidylcholine, phospatidylethanolamine, phosphatidyl serine, phosphatidic acid and cardiolipin (Goldberg et al., 2011). Of these, sphingomyelin is the most widely explored and experimental mouse work has demonstrated that cleaving by neutral sphingomyelinases produce ceramide and phosphocholine. This process is considered important for normal dentine mineralisation (Aubin et al., 2005; Goldberg et al., 2008b). No work has been done to date exploring whether lipids are released from dentine following application of existing PCAs (such as MTA) nor whether these lipids are present in reparative dentine or what their role may be in reparative dentine formation. For these reasons, it is difficult to define what role, if any, these molecules may play in being added to a PCA and, as such, they are not a priority for consideration for inclusion in a PCA; although, further work on their roles in dentine may be beneficial to the wider dental community.

\section{Enamel proteins}

Enamel matrix has long been known to support hard-tissue formation in dental structures and has been used for dental-pulp capping in animal models (Nakamura et al., 2002). However, without knowing the exact composition of the material, it is difficult to know or hypothesise on the roles individual molecules have on tertiary dentine deposition.

Amelogenin and ameloblastin are well known enamel proteins; however, they are also present in dentine and believed to play a role in odontoblast differentiation (Goldberg et al., 2011), supporting the potential role these molecules may play in hard-tissue formation during pulp capping.

Although amelogenin is not present in healthy, mature adult dentine, predentine or pulp, it is present in injured and carious dentine at sites of injury and in newly differentiated odontoblasts. Moreover, it is present during primary dentineogenesis (Mitsiadis et al., 2014). Leading on from this work, researchers have explored the potential role that amelogenin may have in dentine hard-tissue formation for therapeutic effects. For example, it has been explored successfully for apical closure of root canals in dogs (Mounir et al., 2018). Amelogenin exists as several different isotypes and each may have different effects on dentineogenesis. Frasheri et al. (2016) found that no mineralised tissue is produced when DPSCs are exposed to full-length amelogenin. The authors suggested that amelogenin may not act as an inducer for dentine production but as an enhancer.

Ameloblastin is thought to act as a signalling molecule in primary dentineogenesis and dentalpulp complex regeneration (Spahr et al., 2002). One study has explored recombinant ameloblastin (without a carrier) as a PCA in rats, showing that it outperformed $\mathrm{Ca}(\mathrm{OH})_{2}$ (Nakamura et al., 2006). However, fibrosis was found in some of the teeth capped, which could be due either to overdosing with ameloblastin, leading to rapid regenerative activity, or to chronic inflammation caused by the recombinant protein production methods (Nakamura et al., 2006). Either way, this would need addressing and exploring further before ameloblastin can be considered as a definite candidate for a PCA.

The role that some of the enamel proteins may play in reparative dentine formation is still to be completely explored and, as such, their potential use in a PCA. The fact that both ameloblastin and amelogenin have successfully produced hard-tissue barriers in animal models places these molecules as true potential candidates to be used in a PCA, although it is important to better understand the potential dose-dependent results of ameloblastin and how the different amelogenin isotypes affect dentine deposition.

\section{Osteocalcin and calcium-binding proteins}

Osteocalcin is expressed in differentiating odontoblasts (Goldberg et al., 2011) and is often used as a marker of this process.

Osteocalcin is deposited in dentine by odontoblasts, but it is found in bone and cementum too. Although inhibition of osteocalcin is known to inhibit bone production (Ducy et al., 1996), inhibition of osteocalcin (by warfarin) in mice produces no obvious difference in the structure of dentine (Gorter de Vries et al., 1991) 
and excess osteocalcin does not seem to produce any effects on dentine structure either (Bronckers et al., 1998). The purpose of osteocalcin in dentine is not fully elucidated. Ferron et al. (2008) showed that it plays a role in glucose metabolism and may, therefore, be important in facilitating dentine matrix secretion in highly metabolically active odontoblasts, although this needs further clarification.

Osteonectin (also known as SPARC) is expressed in secretory odontoblasts. Osteonectin contains a calcium-binding domain and, as such, is believed to potentially play a role indirectly in dentine formation. However, further work is needed to confirm this (Goldberg et al., 2011).

Other calcium-binding proteins include calmodulin, calbindin, annexines and nucleobindin. Nucelobindin, calbindin and some of the annexines are believed to play a role in transporting calcium into the ECM during dentine deposition (Goldberg et al., 2011).

Insufficient work has been completed on osteocalcin and the calcium-binding proteins found in dentine to fully understand what their role in dentineogenesis is, let alone specifically in reparative dentineogenesis. The fact that inhibition of osteocalcin has little to no effect on dentine production suggests that either the role of osteocalcin is too minor to affect dentine production or that other pathways compensate for the inhibition of this molecule. No work has been done on using osteocalcin or calciumbinding proteins for pulp capping and, as such, this section has been included solely for completeness.

\section{Enzymes}

MMPs are calcium-dependent, zinc-containing enzymes that are sequestered in dentine and play an integral role in development and normal tissue turnover, but also in pathological events.

The main MMPs identified in dentine are MMP8 (a collagenase), MMP-2 and MMP-9 (gelatinases), stromelysin-1 (MMP-3 or proteoglycanase), MMP14 (MT1-MMP, an MMP-2 activator), MMP-13 and enamelysin (MMP-20) (Chaussain et al., 2013). During carious invasion, these entrapped enzymes may be re-exposed or even activated, leading to increased demineralisation and matrix breakdown (Chaussain et al., 2013). Based upon this, MMPs may be an unusual candidate for inclusion in PCAs, however they may either play a role in releasing and activating bioactive molecules from dentine - and so have an overall therapeutic effect on dental-pulp complex regeneration (Chaussain et al., 2013) - or in activating certain molecules (Chaussain et al., 2009). Also, many studies have focused on the use of MMP inhibitors for slowing down the progression of caries (Gendron et al., 1999; Sulkala et al., 2001; Tjaderhane et al., 1999), highlighting the multi-faceted effects these molecules have in the carious tooth.

Based upon the current understanding of these molecules, it may be best to consider these molecules as complicit in carious progression, as the literature proving their role in caries (through exploring MMP inhibitors) currently outweighs the evidence that they may be beneficial to dentine regeneration. As such, it is difficult to ascertain the role these enzymes would play in any PCA.

\section{Discussion}

Most in vivo studies have explored the use of single proteins as bioactive agents within various carriers. Little has been done to explore the use of multiple synergistic bioactive molecules for pulp capping in vivo. Indeed, the synergistic effect of the different peptides may yield more tertiary dentineogenesis and better mimic the physiological conditions of tertiary dentineogenesis since bioactive molecules sequestered in dentine do not work alone but as a collaborative mixture with specific roles in cell migration and cycling and hard tissue regulation and deposition. Therefore, these molecules should be used as a finely tuned and discrete cocktail of the essential components for hard-tissue formation, without causing pulpal obliteration and facilitating an impervious seal of the pulp.

When considering what would be an ideal mix of molecules to use in a PCA, careful deliberation of the role of each molecule needs to be considered - for example, the inclusion of TGF- $\beta 1$ may negate the inclusion of SIBLING molecules due to its role in DSPP release. The inclusion of molecules that encourage the migration, proliferation and differentiation of DPSCs in conjunction with a molecule that will inhibit the reparative dentinogenic process, thereby preventing pulpal obliteration, is recommended. Careful consideration of the spatiotemporal release of these molecules needs to be considered in any PCA design to ensure the correct molecules are released at the correct concentration, at the correct time, and for a suitable period. Preference should be given to molecules capable of producing a dentine hard-tissue phenotype over a bone phenotype to form a more impervious dentine bridge. Some molecules can potentiate the effects of others [for example, the role of PDGF on TGF- $\beta 1$ (Tabatabaei and Torshabi, 2016)], which may help to accelerate the production of a dentine bridge and should be considered for inclusion. Until the safety of some molecules is confirmed - particularly those associated with neoplastic properties - these should not be included in a PCA.

When the pulp gets exposed to toxins from caries (for example lactic acid), it becomes inflamed. There is generally a lack of studies exploring the use of bioactive molecules for pulp capping in inflamed, in vivo, pulp environments. Some authors (such as Rutherford and $\mathrm{Gu}, 2000$ ), have attempted to address this problem. For animal studies to be comparable to clinical work, the experimental setup needs to reflect clinical practice, including carious teeth/inflamed or 
infected pulps, isolation of the tooth, suitable wound lavage, haemostasis and isolation control as well as a suitable restoration. Going forwards, it would be sensible to explore this further with any bioactive molecule considered for inclusion within a pulp cap, to ensure the efficacy of direct pulp capping within an inflamed pulp environment.

Based on the literature, the peptides with the most supporting evidence are TGF- $\beta 1$, BMP-2 and BMP-7. More work is required regarding the other peptides found sequestered in dentine before they can be considered to be appropriate candidates for a PCA, with a focus on in vivo and clinical work. It may be necessary to compare different bioactive molecules, or even biomimetic PCAs, in the same animal models to compare their efficacy. The work by Hu et al. (1998) is a prominent study in this instance, where EGF, IGF, basic FGF, TGF- $\beta 1$, PDGF, $\mathrm{Ca}(\mathrm{OH})_{2}$, a collagen carrier control and a procedure control were compared in the same rat models. Their work demonstrated that TGF- $\beta 1$ induced the best hard- and soft-tissue healing.

It is likely that as work on the biology of dentine continues, more bioactive molecules sequestered in dentine will be discovered. However, many questions on the release of bioactive molecules into dentine remain unanswered, for example:

- Are they released during standard cavity preparation?

- How long is the release sustained for?

- Are they chemically or physically bound in dentine (or both)?

- Do caries influence their release dynamics?

Understanding this may help the design of a biomimetic PCA. It is of course entirely possible that not all molecules sequestered in dentine have a role to play in dentine regeneration and may simply be entombed during the process of primary dentineogenesis. The understanding of all the molecules sequestered in dentine will help a better determination of which are pertinent to tertiary dentine production.

Although some peptides have been explored as PCAs without the use of a carrier, it would be prudent to consider a carrier as an integral part of the creation of a biomimetic PCA. Carriers can allow sustained and timely release of molecules and indeed some have been demonstrated to elicit tertiary dentineogenesis without the need for additional encapsulated factors (Njeh et al., 2016). Some carriers used in the literature are commercially successful PCAs. The carrier can provide some degree of mechanical and structural support, facilitate the migration of DPSCs and affect odontogenic differentiation and mineral deposition (Wang et al., 2011). Some of the carriers explored for bioactive molecules can elicit tertiary dentine bridges even when unloaded (i.e. when they are used as a control without a bioactive molecule added), as shown by Goldberg et al. (2001) using gelatine and Koike et al. (2014) using collagen. These studies raise certain questions and ideas - for example, the potential role of a carrier being an active part of the PCA rather than passively releasing and holding the bioactive components as well as the possibility that the bioactive molecules sequestered in dentine and subsequently released during cavity preparation may be sufficient for dentine bridge formation without additional exogenous molecules.

A short-term area of interest may be to explore the use of existing PCAs coupled with added bioactive molecules, as has already been explored to some extent in the literature, to verify the possibility of overcoming some of the limiting factors of commercially available PCAs. Another possibility would be to utilise existing materials used for bone regeneration in a pulp-capping environment, as many of the molecules cross over, to see what effect these may have and how these may be modified to facilitate dentine production over bone.

Comparing in vivo animal studies is difficult without a clear clinical model comparison. It is important for in vivo work to include a suitable control with which to compare pulp-capping efficacy against. Without agreeing upon a clinically standardised control for use in clinical studies, a suitable control will remain contentious. With many different PCA available commercially, it may be advantageous to compare any experimental PCA against multiple different commercially available materials acting as controls for what is currently achievable in the clinic; although experimentally this may be difficult. Indeed, numerous aspects of the management of a direct pulp cap are open to debate, such as the order of the procedures, the agent used for wound lavage, the agent used for haemostasis, the preferred restorative material and the excavation technique (Bjørndal et al., 2019; Chisini et al., 2015; Munir et al., 2020). Without consensus upon these, agreeing upon a standardised control for animal work will be difficult.

13 years ago, the in vivo effects of TGF- $\beta 1$ and $\mathrm{Ca}(\mathrm{OH})_{2}$ in human sound premolars were compared (Kunarti, 2008). Since then, newer and more effective PCAs have become available and more widely used, which may draw into question whether this is still an avenue that should be explored. With increasing numbers of subjects requiring a functional dentition for a longer time (due to an increased life expectancy), a success rate of $71 \%$ at 6 years (Çalışkan and Güneri, 2017), as for MTA for example, may not be considered a good enough outcome for a surgical procedure in an age of burgeoning regenerative medicine. Dentistry, and specifically regenerative endodontics, could lead the field of regenerative medicine providing more predictable, reproducible and successful treatment outcomes for patients. However, dentistry is falling behind the bone and cartilage regeneration field. Harnessing the innate power of the dental pulp for regeneration may prove useful in the broader field of regenerative medicine, where creation of scaffolds designed around the body's own physiological repair mechanisms may be beneficial. However, considerable optimisation is going to be needed 
before such a material is ready for clinical trials and commercial marketing.

\section{Conclusion}

As there are numerous issues with currently available PCAs, the need for improved physical characteristics and better outcomes when using PCAs is paramount. The utilisation of bioactive molecules in a PCA has the potential to facilitate a more rapid, efficient and successful pulp capping. Tailoring the correct mix of bioactive molecules with the most appropriate carrier is an area that needs more exploration in vivo. Not only would this potentially provide a better outcome for pulp capping, but it may also elucidate the synergistic roles of many of the sequestered molecules in dentine for tertiary dentineogenesis. To date, work has focused on the formation of a dentine bridge, with less work on the regulation and inhibition of this process once successfully completed - which needs consideration to prevent pulpal obliteration, for example, through inclusion of molecules such as SLRPs and SIBLINGs. Successful design of a PCA incorporating a suitable bioactive molecule with a suitable scaffold would allow the pulp native stem cells to migrate, differentiate and successfully create a tertiary dentine bridge. Such a possible clinical outcome probably involves a mixture of certain molecules. TGF $\beta-1$, BMP-7 and BMP-2 have the most evidential support from the literature, with regards to being potential pulp-capping bioactive molecules; although there are numerous limitations to using the BMP family of molecules and other molecules may prove to be more suitable. Considerable optimisation of the various factors and carrier is required to create the most suitable biomimetic PCA (along with exploration of their use in inflamed pulpal tissue) and this is only achievable through high-quality animal and clinical trials, which are still lacking.

\section{References}

Abd-Elmeguid A, Yu DC, Kline LW, Moqbel R, Vliagoftis H (2012) Dentin matrix protein-1 activates dental pulp fibroblasts. J Endod 38: 75-80.

About I, Bottero MJ, De Denato P, Camps J, Franquin JC, Mitsiadis TA (2000a) Human dentin production in vitro. Exp Cell Res 258: 33-41.

About I, Laurent-Maquin D, Lendahl U, Mitsiadis TA (2000b) Nestin expression in embryonic and adult human teeth under normal and pathological conditions. Am J Pathol 157: 287-295.

Agamy HA, Bakry NS, Mounir MMF, Avery DR (2004) Comparison of mineral trioxide aggregate and formocresol as pulp-capping agents in pulpotomized primary teeth. Pediatr Dent 26: 302-309.

Akdis M, Burgler S, Crameri R, Eiwegger T, Fujita H, Gomez E, Klunker S, Meyer N, O’Mahony L, Palomares O, Rhyner C, Quaked N, Schaffartzik
A, Van De Veen W, Zeller S, Zimmermann M, Akdis CA (2011) Interleukins, from 1 to 37, and interferon- $\gamma$ : receptors, functions, and roles in diseases. J Allergy Clin Immunol 127: 701-721.

Åkesson M-L, Wärnberg Gerdin E, Söderström U, Lindahl B, Johansson I (2016) Health-related quality of life and prospective caries development. BMC Oral Health 16: 15. DOI: 10.1186/s12903-016-0166-3.

Aksel H, Huang GTJ (2017) Combined effects of vascular endothelial growth factor and bone morphogenetic protein 2 on odonto/osteogenic differentiation of human dental pulp stem cells in vitro. J Endod 43: 930-935.a

Al-Hassiny A, Hussaini H, Milne T, Seo B, Rich AM, Friedlander LT (2019) Vascularity and angiogenic signaling in the dentine-pulp complex of immature and mature permanent teeth. Eur Endod J 4: 80-85.

Alsanea R, Ravindran S, Fayad MI, Johnson BR, Wenckus CS, Hao J, George A (2011) Biomimetic approach to perforation repair using dental pulp stem cells and dentin matrix protein 1. J Endod 37: 1092-1097.

Andelin WE, Shabahang S, Wright K, Torabinejad M (2003) Identification of hard tissue after experimental pulp capping using dentin sialoprotein (DSP) as a marker. J Endod 29: 646-650.

Arany S, Koyota S, Sugiyama T (2009) Nerve growth factor promotes differentiation of odontoblastlike cells. J Cell Biochem 106: 539-545.

Aubin I, Adams CP, Opsahl S, Septier D, Bishop CE, Auge N, Salvayre R, Negre-Salvayre A, Goldberg M, Guénet JL, Poirier C (2005) A deletion in the gene encoding sphingomyelin phosphodiesterase 3 $(\mathrm{Smpd} 3)$ results in osteogenesis and dentinogenesis imperfecta in the mouse. Nat Genet 37: 803-805.

Austah O, Widbiller M, Tomson PL, Diogenes A (2019) Expression of neurotrophic factors in human dentin and their regulation of trigeminal neurite outgrowth. J Endod 45: 414-419.

Ayoub A, Gillgrass T (2019) The clinical application of recombinant human bone morphogenetic protein 7 for reconstruction of alveolar cleft: 10 years' followup. J Oral Maxillofac Surg 77: 571-581.

Baker SM, Sugars R V., Wendel M, Smith AJ, Waddington RJ, Cooper PR, Sloan AJ (2009) TGF- $\beta$ / extracellular matrix interactions in dentin matrix: a role in regulating sequestration and protection of bioactivity. Calcif Tissue Int 85: 66-74.

Begue-Kirn C, Smith AJ, Loriot M, Kupferle C, Ruch JV, Lesot H (1994) Comparative analysis of TGF $\beta$ s, BMPs, IGF1, msxs, fibronectin, osteonectin and bone sialoprotein gene expression during normal and in vitro-induced odontoblast differentiation. Int J Dev Biol 38: 405-420.

Begue-Kirn C, Smith AJ, Ruch J V., Wozney JM, Purchio A, Hartmann D, Lesot H (1992) Effects of dentin proteins, transforming growth factor $\beta 1$ (TGF $\beta 1$ ) and bone morphogenetic protein 2 (BMP2) on the differentiation of odontoblast in vitro. Int J Dev Biol 36: 491-503. 
Behr B, Sorkin M, Lehnhardt M, Renda A, Longaker MT, Quarto N (2012) A comparative analysis of the osteogenic effects of BMP-2, FGF-2, and VEGFA in a calvarial defect model. Tissue Eng Part A 18: 1079-1086.

Berlanga-Acosta J, Gavilondo-Cowley J, LópezSaura P, González-López T, Castro-Santana MD, López-Mola E, Guillén-Nieto G, Herrera-Martinez L (2009) Epidermal growth factor in clinical practice - a review of its biological actions, clinical indications and safety implications. Int Wound J 6: 331-346.

Bjørndal L, Fransson H, Bruun G, Markvart M, Kjældgaard M, Näsman P, Hedenbjörk-Lager A, Dige I, Thordrup M (2017) Randomized clinical trials on deep carious lesions: 5-year follow-up. J Dent Res 96: 747-753.

Bjørndal L, Simon S, Tomson PL, Duncan HF (2019) Management of deep caries and the exposed pulp. Int Endod J 52: 949-973.

Bleicher F, Richard B, Thivichon-Prince B, Farges JC, Carrouel F (2015). Odontoblasts and dentin formation. In: Stem Cell Biology and Tissue Engineering in Dental Sciences. Chapter 30. Academic Press. pp: 379-395. DOI: 10.1016/B978-0-12-3971579.00034-5.

Brazil DP, Church RH, Surae S, Godson C, Martin F (2015) BMP signalling: agony and antagony in the family. Trends Cell Biol 25: 249-264.

Bronckers ALJJ, Price PA, Schrijvers A, Bervoets TJM, Karsenty G (1998) Studies of osteocalcin function in dentin formation in rodent teeth. Eur J Oral Sci 106: 795-807.

Çalışkan MK, Güneri P (2017) Prognostic factors in direct pulp capping with mineral trioxide aggregate or calcium hydroxide: 2- to 6-year follow-up. Clin Oral Investig 21: 357-367.

Calori GM, Colombo M, Bucci M, Mazza EL, Fadigati P, Mazzola S (2015) Clinical effectiveness of Osigraft in long-bones non-unions. Injury 46: S55-S64.

Catón J, Bringas P, Zeichner-David M (2007) Establishment and characterization of an immortomouse-derived odontoblast-like cell line to evaluate the effect of insulin-like growth factors on odontoblast differentiation. J Cell Biochem 100: 450463.

Chaussain C, Eapen A, Huet E, Floris C, Ravindran S, Hao J, Menashi S, George A (2009) MMP2-cleavage of DMP1 generates a bioactive peptide promoting differentiation of dental pulp stem/progenitor cell. Eur Cells Mater 18: 84-95.

Chaussain C, Boukpessi T, Khaddam M, Tjaderhane L, George A, Menashi S (2013) Dentin matrix degradation by host matrix metalloproteinases: inhibition and clinical perspectives toward regeneration. Front Physiol 4: 308. DOI: 10.3389/ fphys.2013.00308.

Chen S, Gluhak-Heinrich J, Martinez M, Li T, Wu Y, Chuang HH, Chen L, Dong J, Gay I, MacDougall M (2008) Bone morphogenetic protein 2 mediates dentin sialophosphoprotein expression and odontoblast differentiation via NF-Y signaling. J Biol Chem 283: 19359-19370.

Chevet-Noël A, Delord M, Bertrand D, Obert L, Lepage D, Pluvy I, Loisel F (2020) RhBMP7 use for treating scaphoid nonunion: 5 cases assessed at 10 years' follow-up. Hand Surg Rehabil 39: 383-388.

Chisini LA, Conde MCM, Correa MB, Dantas RVF, Silva AF, Pappen FG, Demarco FF (2015) Vital pulp therapies in clinical practice: findings from a survey with dentist in southern Brazil. Braz Dent J 26: 566571.

Cooper PR, Holder MJ, Smith AJ (2014) Inflammation and regeneration in the dentin-pulp complex: a double-edged sword. J Endod 40: S46-S51.

Cooper PR, Takahashi Y, Graham LW, Simon S, Imazato S, Smith AJ (2010) Inflammationregeneration interplay in the dentine-pulp complex. J Dent 38: 687-697.

Corinaldesi G, Piersanti L, Piattelli A, Iezzi G, Pieri F, Marchetti C (2013) Augmentation of the floor of the maxillary sinus with recombinant human bone morphogenetic protein-7: a pilot radiological and histological study in humans. Br J Oral Maxillofac Surg 51: 247-252.

Cullum DR, Kline LW (1985) Pulp response after calcitonin treatment of direct exposures in the dog. Oral Surg Oral Med Oral Pathol 60: 218-223.

Ducy P, Desbois C, Boyce B, Pinero G, Story B, Dunstan C, Smith E, Bonadio J, Goldstein S, Gundberg C, Bradley A, Karsenty G (1996) Increased bone formation in osteocalcin-deficient mice. Nature 382: 448-452.

da Rosa WLO, Piva E, da Silva AF (2018a) Disclosing the physiology of pulp tissue for vital pulp therapy. Int Endod J 51: 829-846.

da Rosa WLO, Cocco AR, da Silva TM, Mesquita LC, Galarça AD, da Silva AF, Piva E (2018b) Current trends and future perspectives of dental pulp capping materials: a systematic review. J Biomed Mater Res B Appl Biomater 106: 1358-1368.

Embery G, Hall R, Waddington R, Septier D, Goldberg M (2001) Proteoglycans in dentinogenesis. Crit Rev Oral Biol Med 12: 331-349.

Ferron M, Hinoi E, Karsenty G, Ducy P (2008) Osteocalcin differentially regulates $\beta$ cell and adipocyte gene expression and affects the development of metabolic diseases in wild-type mice. Proc Natl Acad Sci U S A 105: 5266-5270.

Frasheri I, Ern C, Diegritz C, Hickel R, Hristov M, Folwaczny M (2016) Full-length amelogenin influences the differentiation of human dental pulp stem cells. Stem Cell Res Ther 7: 10. DOI: 10.1186/ s13287-015-0269-9.

Gendron R, Grenier D, Sorsa T, Mayrand D (1999) Inhibition of the activities of matrix metalloproteinases 2, 8, and 9 by chlorhexidine. Clin Diagn Lab Immunol 6: 437-439.

Goldberg M, Farges J, Lacerdapinheiro S, Six N, Jegat N, Decup F, Septier D, Carrouel F, Durand S, Chaussainmiller C (2008a) Inflammatory and 
immunological aspects of dental pulp repair. Pharmacol Res 58: 137-147.

Goldberg M, Kulkarni AB, Young M, Boskey A (2011) Dentin: structure, composition and mineralization. Front Biosci 3: 711-735.

Goldberg M, Opsahl S, Aubin I, Septier D, Chaussain-Miller C, Boskey A, Guenet J-L (2008b) Sphingomyelin degradation is a key factor in dentin and bone mineralization: lessons from the fro/fro mouse. J Dent Res 87: 9-13.

Goldberg M, Six N, Decup F, Buch D, Soheili Majd E, Lasfargues JJ, Salih E, Stanislawski L (2001) Application of bioactive molecules in pulp-capping situations. Adv Dent Res 15: 91-95.

Goldberg M, Septier D, Oldberg A, Young MF, Ameye LG (2006) Fibromodulin-deficient mice display impaired collagen fibrilloqenesis in predentin as well as altered dentin mineralization and enamel formation. J Histochem Cytochem 54: 525-537.

Gorin C, Rochefort GY, Bascetin R, Ying H, Lesieur J, Sadoine J, Beckouche N, Berndt S, Novais A, Lesage M, Hosten B, Vercellino L, Merlet P, Le-Denmat D, Marchiol C, Letourneur D, Nicoletti A, Vital SO, Poliard A, Salmon B, Muller L, Chaussain C, Germain S (2016) Priming dental pulp stem cells with fibroblast growth factor-2 increases angiogenesis of implanted tissue-engineered constructs through hepatocyte growth factor and vascular endothelial growth factor secretion. Stem Cells Transl Med 5: 392-404.

Gorter de Vries I, Wisse E, Williamson MK, Price PA (1991) Effect of warfarin on early rat tooth development. Calcif Tissue Int 49: 355-358.

Graham L, Cooper PR, Cassidy N, Nor JE, Sloan AJ, Smith AJ (2006) The effect of calcium hydroxide on solubilisation of bio-active dentine matrix components. Biomaterials 27: 2865-2873.

Hao J, Narayanan K, Ramachandran A, He G, Almushayt A, Evans C, George A (2002) Odontoblast cells immortalized by telomerase produce mineralized dentin-like tissue both in vitro and in vivo. J Biol Chem 277: 19976-19981.

Hargreaves KM, Cohen S (2010) Cohen's pathways of the pulp 10th edition. Mosby.

Hashemi-Beni B, Khoroushi M, Foroughi MR, Karbasi S, Khademi AA (2017) Tissue engineering: dentin - pulp complex regeneration approaches (a review). Tissue Cell 49: 552-564.

He G, Dahl T, Veis A, George A (2003) Dentin matrix protein 1 initiates hydroxyapatite formation in vitro. Connect Tissue Res 44 Suppl 1: 240-245.

Hilton TJ (2009) Keys to clinical success with pulp capping: a review of the literature. Oper Dent 34 : 615-625.

Hinz B (2015) The extracellular matrix and transforming growth factor- $\beta 1$ : tale of a strained relationship. Matrix Biol 47: 54-65.

Hong KS, Kim EC, Bang SH, Chung CH, Lee YI, Hyun JK, Lee HH, Jang JH, Kim TI, Kim HW (2010) Bone regeneration by bioactive hybrid membrane containing FGF2 within rat calvarium. J Biomed Mater Res A 94: 1187-1194.
Howard C, Murray PE, Namerow KN (2010) Dental pulp stem cell migration. J Endod 36: 19631966.

Hu CC, Zhang C, Qian Q, Tatum NB (1998) Reparative dentin formation in rat molars after direct pulp capping with growth factors. J Endod 24: 744751.

Hu JC-C, Zhang C, Yun S-S, Qian Q, Ranly DM (1997) Platelet-derived growth factor-BB and epidermal growth factor as pulp capping medicaments in rat incisors. J Hard Tissue Biol 6: 121-129.

Iohara $\mathrm{K}$, Nakashima $\mathrm{M}$, Ito $\mathrm{M}$, Ishikawa $\mathrm{M}$, Nakasima A, Akamine A (2004) Dentin regeneration by dental pulp stem cell therapy with recombinant human bone morphogenetic protein 2. J Dent Res 83: 590-595.

Iohara K, Murakami M, Takeuchi N, Osako Y, Ito M, Ishizaka R, Utunomiya S, Nakamura H, Matsushita K, Nakashima M (2013) A novel combinatorial therapy with pulp stem cells and granulocyte colony-stimulating factor for total pulp regeneration. Stem Cells Transl Med 2: 521-533.

Ishimatsu H, Kitamura C, Morotomi T, Tabata Y, Nishihara T, Chen KK, Terashita M (2009) Formation of dentinal bridge on surface of regenerated dental pulp in dentin defects by controlled release of fibroblast growth factor-2 from gelatin hydrogels. J Endod 35: 858-865.

Kigami R, Sato S, Tsuchiya N, Yoshimakai T, Arai Y, Ito K (2013) FGF-2 angiogenesis in bone regeneration within critical-sized bone defects in rat calvaria. Implant Dent 22: 422-427.

Kikuchi N, Kitamura C, Morotomi T, Inuyama Y, Ishimatsu H, Tabata Y, Nishihara T, Terashita M (2007) Formation of dentin-like particles in dentin defects above exposed pulp by controlled release of fibroblast growth factor 2 from gelatin hydrogels. J Endod 33: 1198-1202.

Kim J-H, Hong J-B, Lim B-S, Cho B-H (2009) Histological evaluation of direct pulp capping with DSP-derived synthetic peptide in beagle dog. J Korean Acad Conserv Dent 34: 120. DOI: 10.5395/ jkacd.2009.34.2.120.

Kim SY, Lee SM, Lee JH (2019) Initial cytotoxicity of mineral trioxide aggregate (MTA) during setting on human mesenchymal stem cells. Adv Mater Sci Eng 2019. DOI: 10.1155/2019/2365104.

Kinnaird T, Stabile E, Burnett MS, Shou M, Lee CW, Barr S, Fuchs S, Epstein SE (2004) Local delivery of marrow-derived stromal cells augments collateral perfusion through paracrine mechanisms. Circulation 109: 1543-1549.

Kitamura K, Kangawa K, Kawamoto M, Ichiki Y, Nakamura S, Matsuo H, Eto T (1993) Adrenomedullin: a novel hypotensive peptide isolated from human pheochromocytoma. Biochem Biophys Res Commun 192: 553-560.

Kline LW, Yu DC (2009) Effects of calcitonin, calcitonin gene-related peptide, human recombinant bone morphogenetic protein-2, and parathyroid 
hormone-related protein on endodontically treated ferret canines. J Endod 35: 866-869.

Ko H, Yang W, Park K, Kim M (2010) Cytotoxicity of mineral trioxide aggregate (MTA) and bone morphogenetic protein 2 (BMP-2) and response of rat pulp to MTA and BMP-2. Oral Surg Oral Med Oral Pathol Oral Radiol Endod 109: e103-e108.

Koike T, Polan MAA, Izumikawa M, Saito T (2014) Induction of reparative dentin formation on exposed dental pulp by dentin phosphophoryn/ collagen composite. Biomed Res Int 2014: 745139. DOI: $10.1155 / 2014 / 745139$.

Kunarti S (2008) Pulp tissue inflammation and angiogenesis after pulp capping with transforming growth factor $\beta 1$. Dent J (Majalah Kedokt. Gigi) 41: 88. DOI: 10.20473/j.djmkg.v41.i2.p88-90.

Li F, Liu X, Zhao S, Wu H, Xu HHK (2014) Porous chitosan bilayer membrane containing TGF- $\beta 1$ loaded microspheres for pulp capping and reparative dentin formation in a dog model. Dent Mater 30: 172-181.

Li L, Wang Z (2016) PDGF-BB, NGF and BDNF enhance pulp-like tissue regeneration: via cell homing. RSC Adv 6: 109519-109527. DOI: 10.1039/ c6ra20290j.

Li W, Chen L, Chen Z, Wu L, Feng J, Wang F, Shoff L, Li X, Donly KJ, MacDougall M, Chen S (2017) Dentin sialoprotein facilitates dental mesenchymal cell differentiation and dentin formation. Sci Rep 7: 300. DOI: 10.1038/s41598-017-00339-w.

Lim W, Bae H, Bazer FW, Song G (2017) Stimulatory effects of fibroblast growth factor 2 on proliferation and migration of uterine luminal epithelial cells during early pregnancy. Biol Reprod 96: 185-198.

Linsuwanont P, Wimonsutthikul K, Pothimoke U, Santiwong B (2017) Treatment outcomes of mineral trioxide aggregate pulpotomy in vital permanent teeth with carious pulp exposure: the retrospective study. J Endod 43: 225-230.

Lipski M, Nowicka A, Kot K, Postek-Stefańska L, Wysoczańska-Jankowicz I, Borkowski L, Andersz P, Jarząbek A, Grocholewicz K, Sobolewska E, Woźniak K, Droździk A (2018) Factors affecting the outcomes of direct pulp capping using biodentine. Clin Oral Investig 22: 2021-2029.

Listik E, Azevedo Marques Gaschler J, Matias M, Neuppmann Feres MF, Toma L, Raphaelli NahásScocate AC (2019) Proteoglycans and dental biology: the first review. Carbohydr Polym 225: 115199. DOI: 10.1016/j.carbpol.2019.115199.

Listl S, Galloway J, Mossey PA, Marcenes W (2015) Global economic impact of dental diseases. J Dent Res 94: 1355-1361.

Lovschall H, Fejerskov O, Flyvbjerg A (2001) Pulp-capping with recombinant human insulin-like growth factor I (rhIGF-I) in rat molars. Adv Dent Res 15: 108-112.

Lv T, Wu Y, Mu C, Liu G, Yan M, Xu X, Wu H, Du J, Yu J, Mu J (2016) Insulin-like growth factor 1 promotes the proliferation and committed differentiation of human dental pulp stem cells through MAPK pathways. Arch Oral Biol 72: 116-123.

Matsumura S, Quispe-Salcedo A, Schiller CM, Shin JS, Locke BM, Yakar S, Shimizu E (2017) IGF-1 mediates ephrin $\mathrm{Bl}$ activation in regulating tertiary dentin formation. J Dent Res 96: 1153-1161.

Matsushita K, Motani R, Sakuta T, Yamaguchi N, Koga T, Matsuo K, Nagaoka S, Abeyama K, Maruyama I, Torii M (2000) The role of vascular endothelial growth factor in human dental pulp cells: induction of chemotaxis, proliferation, and differentiation and activation of the AP-1-dependent signaling pathway. J Dent Res 79: 1596-1603.

McCoy RJ, Widaa A, Watters KM, Wuerstle M, Stallings RL, Duffy GP, O’Brien FJ (2013) Orchestrating osteogenic differentiation of mesenchymal stem cells - identification of placental growth factor as a mechanosensitive gene with a pro-osteogenic role. Stem Cells 31: 2420-2431.

McLachlan JL, Smith AJ, Sloan AJ, Cooper PR (2003) Gene expression analysis in cells of the dentinepulp complex in healthy and carious teeth. Arch Oral Biol 48: 273-283.

Mente J, Hufnagel S, Leo M, Michel A, Gehrig H, Panagidis D, Saure D, Pfefferle T (2014) Treatment outcome of mineral trioxide aggregate or calcium hydroxide direct pulp capping: long-term results. J Endod 40: 1746-1751.

Mitsiadis TA, Filatova A, Papaccio G, Goldberg M, About I, Papagerakis P (2014) Distribution of the amelogenin protein in developing, injured and carious human teeth. Front Physiol 5: 477. DOI: 10.3389/fphys.2014.00477.

Mounir MMF, Farsi JMA, Alhazzazi TY, Matar MA, El-Housseiny AA (2018) Characterization of the apical bridge barrier formed following amelogenin apexification. BMC Oral Health 18: 201. DOI: 10.1186/ s12903-018-0641-0.

Munir A, Zehnder M, Rechenberg DK (2020) Wound lavage in studies on vital pulp therapy of permanent teeth with carious exposures: a qualitative systematic review. J Clin Med 9: 984. DOI: 10.3390/ jcm9040984.

Murray PE, Lumley PJ, Hafez AA, Cox CF, Smith AJ (2002) Preserving the vital pulp in operative dentistry: 4. Factors influencing successful pulp capping. Dent Update 29: 225-233.

Musson DS, McLachlan JL, Sloan AJ, Smith AJ, Cooper PR (2010) Adrenomedullin is expressed during rodent dental tissue development and promotes cell growth and mineralization. Biol Cell 102: $145-157$.

Nakamura Y, Hammarström L, Matsumoto K, Lyngstadaas SP (2002) The induction of reparative dentine by enamel proteins. Int Endod J 35: 407-417.

Nakamura Y, Slaby I, Spahr A, Pezeshki G, Matsumoto K, Lyngstadaas SP (2006) Ameloblastin fusion protein enhances pulpal healing and dentin formation in porcine teeth. Calcif Tissue Int 78: 278284. 
Nakashima M (1992) The effects of growth factors on DNA synthesis, proteoglycan synthesis and alkaline phosphatase activity in bovine dental pulp cells. Arch Oral Biol 37: 231-236.

Nakashima M (1994a) Induction of dentine in amputated pulp of dogs by recombinant human bone morphogenetic proteins-2 and -4 with collagen matrix. Arch Oral Biol 39: 1085-1089.

Nakashima M (1994b) Induction of dentin formation on canine amputated pulp by recombinant human bone morphogenetic proteins (BMP)-2 and -4 . J Dent Res 73: 1515-1522.

Nakashima M, Iohara K (2017) Recent progress in translation from bench to a pilot clinical study on total pulp regeneration. J Endod 43: S82-S86.

Nakashima M, Reddi AH (2003) The application of bone morphogenetic proteins to dental tissue engineering. Nat Biotechnol 21: 1025-1032.

Narayanan K, Srinivas R, Ramachandran A, Hao J, Quinn B, George A (2001) Differentiation of embryonic mesenchymal cells to odontoblast-like cells by overexpression of dentin matrix protein 1 . Proc Natl Acad Sci U S A 98: 4516-4521.

Niwa T, Yamakoshi Y, Yamazaki H, Karakida T, Chiba R, Hu JCC, Nagano T, Yamamoto R, Simmer JP, Margolis HC, Gomi K (2018) The dynamics of TGF- $\beta$ in dental pulp, odontoblasts and dentin. Sci Rep 8: 4450. DOI: 10.1038/s41598-018-22823-7.

Njeh A, Uzunoğlu E, Ardila-Osorio H, Simon S, Berdal A, Kellermann O, Goldberg M (2016) Reactionary and reparative dentin formation after pulp capping: hydrogel vs. dycal. Evidence-Based Endod 1: 3. DOI: 10.1186/s41121-016-0003-9.

Ohnishi T, Suwa M, Oyama T, Arakaki N, Torii M, Daikuhara Y (2000) Prostaglandin E2 predominantly induces production of hepatocyte growth factor/ scatter factor in human dental pulp in acute inflammation. J Dent Res 79: 748-755.

Ohnishi T, Daikuhara Y (2003) Hepatocyte growth factor/scatter factor in development, inflammation and carcinogenesis: Its expression and role in oral tissues. Arch Oral Biol 48: 797-804.

Oliva-Rodríguez R, Pérez-Urizar J, DibildoxAlvarado E, Martínez-Saldaña MC, Avelar-González FJ, Flores-Reyes H, Pozos-Guillén ADJ, GuerreroBarrera AL (2011) Design of a controlled release system of OP-1 and TGF- $\beta 1$ based in microparticles of sodium alginate and release characterization by HPLC-UV. In Vitro Cell Dev Biol Anim 47: 681-688.

Orsini G, Ruggeri A, Mazzoni A, Nato F, Manzoli L, Putignano A, Di Lenarda R, Tjäderhane L, Breschi L (2009) A review of the nature, role, and function of dentin non-collagenous proteins. Part 1: proteoglycans and glycoproteins. Endod Top 21: 1-18.

Pan S, Dangaria S, Gopinathan G, Yan X, Lu X, Kolokythas A, Niu Y, Luan X (2013) SCF Promotes dental pulp progenitor migration, neovascularization, and collagen remodeling - potential applications as a homing factor in dental pulp regeneration. Stem Cell Rev Rep 9: 655-667.
Paula AB, Laranjo M, Marto CM, Paulo S, Abrantes AM, Casalta-Lopes J, Marques-Ferreira M, Botelho MF, Carrilho E (2018) Direct pulp capping: what is the most effective therapy? - systematic review and meta-analysis. J Evid Based Dent Pract 18: 298-314.

Qu T, Jing J, Ren Y, Ma C, Feng JQ, Yu Q, Liu X (2015) Complete pulpodentin complex regeneration by modulating the stiffness of biomimetic matrix. Acta Biomater 16: 60-70.

Qureshi A, Soujanya E, Kumar N, Kumar P, Hivarao S (2014) Recent advances in pulp capping materials: an overview. J Clin Diagn Res 8: 316-321.

Rambhia KJ, Ma PX (2015) Controlled drug release for tissue engineering. J Control Release 219: 119-128.

Ritter AV (2007) Direct pulp-capping performed by dental students has a success rate close to $60 \%$. Direct capping of carious pulp exposures is significantly less successful $(33 \%)$ than direct capping of mechanical pulp exposures (92\%). J Evid Based Dent Pract 7: 165-166.

Roberts-Clark DJ, Smith AJ (2000) Angiogenic growth factors in human dentine matrix. Arch Oral Biol 45: 1013-1016.

Ruangsawasdi N, Zehnder M, Patcas R, Ghayor C, Siegenthaler B, Gjoksi B, Weber FE (2017) Effects of stem cell factor on cell homing during functional pulp regeneration in human immature teeth. Tissue Eng Part A 23: 115-123.

Rutherford RB, Gu K (2000) Treatment of inflamed ferret dental pulps with recombinant bone morphogenetic protein-7. Eur J Oral Sci 108: 202-206.

Rutherford RB, Spångberg L, Tucker M, Rueger D, Charette M (1994) The time-course of the induction of reparative dentine formation in monkeys by recombinant human osteogenic protein-1. Arch Oral Biol 39: 833-838.

Rutherford RB, Wahle J, Tucker M, Rueger D, Charette M (1993) Induction of reparative dentine formation in monkeys by recombinant human osteogenic protein-1. Arch Oral Biol 38: 571-576.

Rutherford RB (2001) Short communication BMP7 gene transfer to inflamed ferret dental pulps. Eur J Oral Sci 109: 422-424.

Sailhan F, Gleyzolle B, Parot R, Guerini H, Viguier E (2010) Rh-BMP-2 in distraction osteogenesis: dose effect and premature consolidation. Injury 41: 680686.

Saito K, Nakatomi M, Ida-Yonemochi H, Ohshima $\mathrm{H}$ (2016) Osteopontin is essential for type I collagen secretion in reparative dentin. J Dent Res 95: 10341041.

Saito K, Nakatomi M, Ida-Yonemochi H, Kenmotsu S, Ohshima H (2011) The expression of GM-CSF and osteopontin in immunocompetent cells precedes the odontoblast differentiation following allogenic tooth transplantation in mice. J Histochem Cytochem 59: 518-529.

Schmalz G, Widbiller M, Galler KM (2017) Signaling molecules and pulp regeneration. J Endod 43: S7-S11. 
Simon S, Smith AJ, Berdal A, Lumley PJ, Cooper PR (2010) The MAP kinase pathway is involved in odontoblast stimulation via p38 phosphorylation. J Endod 36: 256-259.

Six N, Decup F, Lasfargues JJ, Salih E, Goldberg M (2002a) Osteogenic proteins (bone sialoprotein and bone morphogenetic protein-7) and dental pulp mineralization. J Mater Sci Mater Med 13: 225-232.

Six N, Septier D, Chaussain-Miller C, Blacher R, DenBesten P, Goldberg M (2007) Dentonin, a MEPE fragment initiates pulp-healing response to injury. J Dent Res 86: 780-785.

Six N, Lasfargues JJ, Goldberg M (2002b) Differential repair responses in the coronal and radicular areas of the exposed rat molar pulp induced by recombinant human bone morphogenetic protein 7 (osteogenic protein 1). Arch Oral Biol 47: 177-187.

Sloan AJ (2015) Biology of the dentin-pulp complex. In: Stem cell biology and tissue engineering in dental sciences. Editors: Vishwakarma A, Sharpe P, Shi S, Ramalingam M. Elsevier. pp: 371-378. DOI: 10.1016/B978-0-12-397157-9.00033-3.

Smith AJ, Scheven BA, Takahashi Y, Ferracane JL, Shelton RM, Cooper PR (2012) Dentine as a bioactive extracellular matrix. Arch Oral Biol 57: 109-121.

Smith AJ (2003) Vitality of the dentin-pulp complex in health and disease: growth factors as key mediators. J Dent Educ 67: 678-689.

Smith AJ, Duncan HF, Diogenes A, Simon S, Cooper PR (2016) Exploiting the bioactive properties of the dentin-pulp complex in regenerative endodontics. J Endod 42: 47-56.

Smith HS, Soni NN (1982) Histologic study of pulp capping in rat molars using calcitonin. Oral Surg Oral Med Oral Pathol 53: 311-317.

Spahr A, Lyngstadaas SP, Slaby I, Haller B, Boeckh C, Tsoulfidou F, Hammarstrom L (2002) Expression of amelin and trauma-induced dentin formation. Clin Oral Investig 6: 51-57.

Stankoska K, Sarram L, Smith S, BedranRusso AK, Little CB, Swain M V., Bertassoni LE (2016) Immunolocalization and distribution of proteoglycans in carious dentine. Aust Dent J 61: 288-297.

Stanley HR, Pameijer CH (1997) Dentistry's friend: calcium hydroxide. Oper Dent 22: 1-3.

Sulkala M, Wahlgren J, Larmas M, Sorsa T, Teronen O, Salo T, Tjäderhane L (2001) The effects of MMP inhibitors on human salivary MMP activity and caries progression in rats. J Dent Res 80: 1545-1549.

Suzuki T, Lee CH, Chen M, Zhao W, Fu SY, Qi JJ, Chotkowski G, Eisig SB, Wong A, Mao JJ (2011) Induced migration of dental pulp stem cells for in vivo pulp regeneration. J Dent Res 90: 1013-1018.

Tabatabaei FS, Torshabi M (2016) Effects of non-collagenous proteins, TGF- $\beta 1$, and PDGF-BB on viability and proliferation of dental pulp stem cells. J Oral Maxillofac Res 7: e4. DOI: 10.5037/ jomr.2016.7104.

Takeuchi N, Hayashi Y, Murakami M, Alvarez FJ, Horibe H, Iohara K, Nakata K, Nakamura H,
Nakashima M (2015) Similar in vitro effects and pulp regeneration in ectopic tooth transplantation by basic fibroblast growth factor and granulocyte-colony stimulating factor. Oral Dis 21: 113-122.

Teng CF, Jeng L Bin, Shyu WC (2018) Role of insulin-like growth factor 1 receptor signaling in stem cell stemness and therapeutic efficacy. Cell Transplant 27: 1313-1319.

Tjaderhane L, Sulkala M, Sorsa T, Teronen O, Larmas M, Salo T (1999) The effect of MMP inhibitor metastat on fissure caries progression in rats. Ann $\mathrm{N}$ Y Acad Sci 878: 686-688.

Tomson PL, Lumley PJ, Smith AJ, Cooper PR (2017) Growth factor release from dentine matrix by pulp-capping agents promotes pulp tissue repairassociated events. Int Endod J 50: 281-292.

Tomson PL, Lumley PJ, Alexander MY, Smith AJ, Cooper PR (2013) Hepatocyte growth factor is sequestered in dentine matrix and promotes regeneration-associated events in dental pulp cells. Cytokine 61: 622-629.

Trapnell BC, Abe S (2006) Colony stimulating factors. In: Encyclopedia of Respiratory Medicine. Editors: GJ Laurent, SD Shapiro. pp: 540-546.

Tüzüner T, Alacam A, Altunbas DA, Gokdogan FG, Gundogdu E (2012) Clinical and radiographic outcomes of direct pulp capping therapy in primary molar teeth following haemostasis with various antiseptics: a randomised controlled trial. Eur J Paediatr Dent 13: 289-292.

Tziafas D, Alvanou A, Papadimitriou S, Gasic J, Komnenou A (1998) Effects of recombinant basic fibroblast growth factor, insulin-like growth factorII and transforming growth factor- $\beta 1$ on dog dental pulp cells in vivo. Arch Oral Biol 43: 431-444.

Tziafas D, Kodonas K, Gogos C, Tziafa C, Papadimitriou S (2017) Dentine-pulp tissue engineering in miniature swine teeth by set calcium silicate containing bioactive molecules. Arch Oral Biol 73: 230-236.

Vander Ark A, Cao J, Li X (2018) TGF- $\beta$ receptors: In and beyond TGF- $\beta$ signaling. Cell Signal 52: 112120.

Vincentelli AF, Szadkowski M, Vardon D, Litrico S, Fuentès S, Steib JP, Le Huec JC, Huppert J, Dubois G, Lenoir T, Sailhan F, Passuti N (2019) rhBMP-2 (recombinant human bone morphogenetic protein-2) in real world spine surgery. A phase IV, national, multicentre, retrospective study collecting data from patient medical files in French spinal centres. Orthop Traumatol Surg Res 105: 1157-1163.

Wang J, Liu X, Jin X, Ma H, Hu J, Ni L, Ma PX (2010) The odontogenic differentiation of human dental pulp stem cells on nanofibrous poly(l-lactic acid) scaffolds in vitro and in vivo. Acta Biomater 6: 3856-3863.

Wang J, Ma H, Jin X, Hu J, Liu X, Ni L, Ma PX (2011) The effect of scaffold architecture on odontogenic differentiation of human dental pulp stem cells. Biomaterials 32: 7822-7830.

Wu S, Zhou Y, Yu Y, Zhou X, Du W, Wan M, Fan Y, Zhou X, Xu X, Zheng L (2019) Evaluation 
of chitosan hydrogel for sustained delivery of VEGF for odontogenic differentiation of dental pulp stem cells. Stem Cells Int 2019: 1515040. DOI: 10.1155/2019/1515040.

Xiao N, Thor D, Yu WY (2020) Neurotrophins BDNF and NT4/5 accelerate dental pulp stem cell migration. Biomed J 44: 363-368.

Xiao N, Yu WY, Liu D (2018) Glial cell-derived neurotrophic factor promotes dental pulp stem cell migration. J Tissue Eng Regen Med 12: 705-714.

Xu Q, Zhang Q, Ishida Y, Hajjar S, Tang X, Shi H, Dang CV, Le AD (2017) EGF induces epithelialmesenchymal transition and cancer stem-like cell properties in human oral cancer cells via promoting Warburg effect. Oncotarget 8: 9557-9571.

Yang X, Van Der Kraan PM, Bian Z, Fan M, Walboomers XF, Jansen JA (2009) Mineralized tissue formation by BMP2-transfected pulp stem cells. J Dent Res 88: 1020-1025.

Yang X, Han G, Pang X, Fan M (2012) Chitosan/ collagen scaffold containing bone morphogenetic protein-7 DNA supports dental pulp stem cell differentiation in vitro and in vivo. J Biomed Mater Res A 108: 2519-2526.

Ye L, Peng L, Tan H, Zhou X (2006) HGF enhanced proliferation and differentiation of dental pulp cells. J Endod 32: 736-741.

Youssef AR, Emara R, Taher MM, Al-Allaf FA, Almalki M, Almasri MA, Siddiqui SS (2019) Effects of mineral trioxide aggregate, calcium hydroxide, biodentine and emdogain on osteogenesis, odontogenesis, angiogenesis and cell viability of dental pulp stem cells. BMC Oral Health 19: 133. DOI: 10.1186/s12903-019-0827-0.

Zafar K, Jamal S, Ghafoor R (2020) Bio-active cements-mineral trioxide aggregate based calcium silicate materials: a narrative review. J Pak Med Assoc 70: 497-504.

Zhang J, Lian M, Cao P, Bao G, Xu G, Sun Y, Wang L, Chen J, Wang Y, Feng G, Cui Z (2017a) Effects of nerve growth factor and basic fibroblast growth factor promote human dental pulp stem cells to neural differentiation. Neurochem Res 42: 1015-1025.

Zhang M, Jiang F, Zhang X, Wang S, Jin Y, Zhang W, Jiang $X(2017 b)$ The effects of platelet-derived growth factor-bb on human dental pulp stem cells mediated dentin-pulp complex regeneration. Stem Cells Transl Med 6: 2126-2134.

Zhang R, Cooper PR, Smith G, Nör JE, Smith AJ (2011) Angiogenic activity of dentin matrix components. J Endod 37: 26-30.

Zhang W, Walboomers XF, Jansen JA (2008) The formation of tertiary dentin after pulp capping with a calcium phosphate cement, loaded with PLGA microparticles containing TGF- $\beta 1$. J Biomed Mater Res A 85: 439-444.

Zhang W, Liu W, Ling J, Lin Z, Gao Y, Mao X, Jian $Y$ (2014) Odontogenic differentiation of vascular endothelial growth factor-transfected human dental pulp stem cells in vitro. Mol Med Rep 10: 1899-1906.
Zhao S, Sloan AJ, Murray PE, Lumley PJ, Smith AJ (2000) Ultrastructural localisation of TGF- $\beta$ exposure in dentine by chemical treatment. Histochem J 32: 489-494.

Zhu C, Ju B, Ni R (2015) Clinical outcome of direct pulp capping with MTA or calcium hydroxide: a systematic review and meta-analysis. Int J Clin Exp Med 8: 17055-17060.

Zhu L, Ma J, Mu R, Zhu R, Chen F, Wei X, Shi X, Zang S, Jin L (2018) Bone morphogenetic protein 7 promotes odontogenic differentiation of dental pulp stem cells in vitro. Life Sci 202: 175-181.

Zhu Q, Gao J, Tian G, Tang Z, Tan Y (2017) Adrenomedullin promotes the odontogenic differentiation of dental pulp stem cells through CREB/BMP2 signaling pathway. Acta Biochim Biophys Sin (Shanghai) 49: 609-616.

Zhu Q, Tian G, Tang Z, Gao J, Tan Y (2016) Adrenomedullin promotes the proliferation and inhibits apoptosis of dental pulp stem cells involved in divergence pathways. J Endod 42: 1347-1354.

Zohrabian VM, Poon CS, Abrahams JJ (2015) Embryology and anatomy of the jaw and dentition. Semin Ultrasound CT MR 36: 397-406.

\section{Web Reference}

1. https://www.who.int/news-room/fact-sheets/ detail/oral-health [07.10.2021]

\section{Discussion with Reviewer}

Pierfrancesco Pagella: What is, according to the authors, the ideal characteristic of a pulp-capping material? What is their ideal goal concerning induction of mineralisation, resolution of the inflammatory response and neovascularisation?

Authors: Many different authors have expressed different opinions on the 'ideal characteristics of a pulp-capping material' and we have mentioned one such example, which we feel matches the current requirements of any new pulp-capping material. However, if we were to pick just one characteristic it would be for the material to be biocompatible and non-toxic. The ideal goal would be to control inflammation and induce mineralisation. Some inflammation is necessary for reparative dentineogenesis, so complete resolution of inflammation would not be suitable. Indeed, it could be argued that placing any material on the pulp would likely induce some degree of inflammatory response. As such, we would advocate 'control' of inflammation, to a level assisting regeneration rather than resolution. The induction of a dentine bridge is of paramount importance to seal the pulp. If the pulp is vital (which is the only scenario when a pulp cap is traditionally attempted), it will have patent vessels and inflammation typically leads to some degree of 
neovascularisation, so neovascularisation is likely to be less of an issue for a direct pulp-capping material.
Editor's note: The Scientific Editor responsible for this paper was Thimios Mitsiadis. 